\title{
[4]
}

\section{Aesthetics at Home}

The main aesthetic forms that I consider in this chapter on the homes of Tidewater are architecture and architectural space, internal decor and furnishings, food, gardens and landscaping, and leisure activities.

The history of settlement in Tidewater has had a clear effect on local architecture and its aesthetics. Houses can be divided into those built (1) between 1860 and 1929, before the road to the mainland was constructed, (2) between 1930 and 1950, the first period of expansion after the road came through, and (3) after 1950, the later expansion. Although the land was owned and settled earlier, no house survives that was built before 1860 . Houses from period 1 are typically two rooms wide, two stories high, and one room deep. Period 2 houses are predominantly small, cabinlike structures. The houses of period 3 are either mobile homes situated in block lots planned for that purpose or brick-veneer frame houses with a great variety of floor plans.

The vocabulary of this typology and the chronology associated with it are my own, but these groupings have broad local currency. "Old house" in local language, for example, invariably means a period 1 house, and "brick house" or "mobile home" is used to identify period 3 houses. Period 2 houses form a residual category identified in various ways, mostly referring to their smallness or cheapness of construction: "small place," "a nothing house," or "a cheap old place." I use my chronological typology rather than local terms because the time spans are important to an understanding of the building practices involved and related aesthetic decisions.

The houses of period 1, the homesteads of the oldest families in the community, are spaced evenly along the road, sometimes with newer 
houses between or behind them where owners have sold off building plots. Although many of these houses were built as central-hallway houses, with two rooms on each of two floors, a substantial proportion started out as humbler dwellings, and all have been structurally altered since they were erected. Schematically the downstairs rooms in the original houses were arranged as in Figure 2. The two upstairs rooms were identical in size and position to those downstairs. Kitchen, dining room, and toilet were separate buildings located close to the rear of the house. Characteristically the house was built with an open front porch.

Many of the basic features of this house serve utilitarian ends. The central hall with opposite front and back doors provided a breezeway in summer, and the separate kitchen kept the heat from cooking away from the main living space. In the winter the doors of the living and sitting rooms could be closed to provide small heatable units, avoiding the expenditure of energy to heat unused or rarely used space. These aspects of the house appear purely functional, but they also have aesthetic and psychological dimensions.

A central hallway and closed-off rooms reflect, Henry Glassie (1975:190) suggests, a desire for privacy. A visitor admitted to the hallway is still in limbo between the outside and the main living area. Aspects of the house other than the basic room plan are also important. The front porch was (and still is) a major part of the house; there

Figure 2. Downstairs floor plan for basic period 1 house

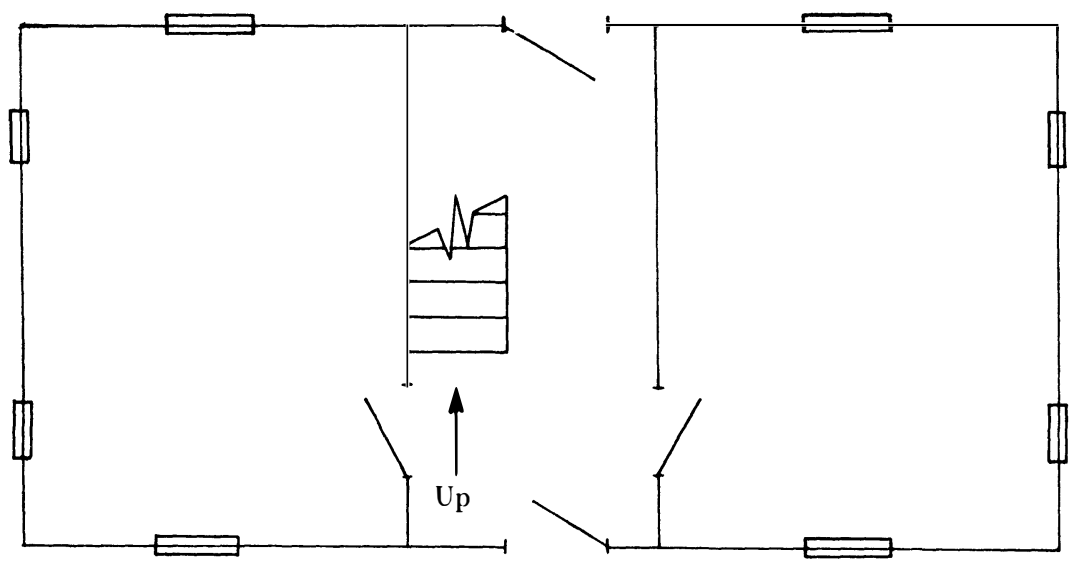


residents sat in the afternoons to catch a-cooling breeze and kept an eye on passersby. Far from withdrawing from the world, they relaxed in the most open part of the house. Admittedly the house provided a retreat should it be needed, but clearly the psychological needs of the occupants were complex. Adequate provision was made both for exposure and for seclusion, so that this type of house gives the occupants a fundamental choice between confinement and openness. However, the basic house plan does not supply the analyst with sufficient firm clues regarding the psychological advantages and disadvantages of particular features. One must see the house in use to understand how space is used and what it means to its occupants. This information in turn helps interpret the aesthetics of architectural space and its relationship to other aesthetic forms, such as decor. Also, patterned changes in the basic house indicate changes in usage and desires and so affect aesthetic decisions.

The first change in these older houses came in the 1930s, when the kitchen and dining-room units were butted up against the main house and roofed continuously with it to form an ell. In some cases a second story was added to the ell and divided into two bedrooms. Some of the older people in Tidewater, indicative of times before this change, still refer to going from the kitchen to the living room as "going into the house." The main incentive for this structural change was the advent of indoor plumbing; electric lines were run along the new highway in the 1930s and the electricity was used to power water pumps. Indoor plumbing demanded a compromise. Moving the kitchen closer to the house made the living space hotter, but it made the plumbing cheaper and more efficient. Bathrooms were installed in the house. To have a separate kitchen with running water would have required two plumbing systems, which was clearly impractical.

Two other changes have taken place in the last few decades. Hallways have been dispensed with in many of the houses, and the porches have been screened or walled in. The hallway is easily dispensed with by taking down the partition wall opposite the staircase, as in Figure 3. The visitor enters directly into the living area, and the hallway is converted into usable space. Even so the breezeway remains useful, and there is a room to withdraw to in the winter. In effect two aesthetically distinct spaces are created by this change. Two roughly equivalent living spaces-that is, spaces of approximately the same size and both opening on to the central hallway in a symmetrically balanced way-are now asymmetrical, with different spatial qualities. The old "den," the left-hand room in Figure 3, retains its 
former characteristics. It is fully enclosed and confined, providing an intimate space. By contrast, the other room, the "living room," is opened up in several ways. It is, of course, bigger, but the general feeling created by the space is even more expansive because doors from this room now open directly on the front and back yards and the staircase at the end leads up to the second floor. The breezeway continues to function, but it helps circulate air through the entire room, and the open front and back doors provide additional light. I consider how these spaces function later in this chapter. For now I simply note that the new room configuration gives the occupant a choice between a more closed and a more open space for a range of tasks. This choice was cited by all the people who had made the structural change as their prime motivation.

Screening in porches might have occurred sooner had it been technologically or financially possible, for obvious reasons. The swamp is a breeding ground for all manner of stinging and biting insects, and a hot day in July is pure torment for anyone out in the open. Yet this structural change also involved a compromise. The very openness of the porch was dramatically reduced, and those sitting on the porch became largely hidden from view. Screened-in porches are like twoway mirrors in that those inside can look out easily but those outside

Figure 3. Downstairs floor plan for basic period 1 house after modification

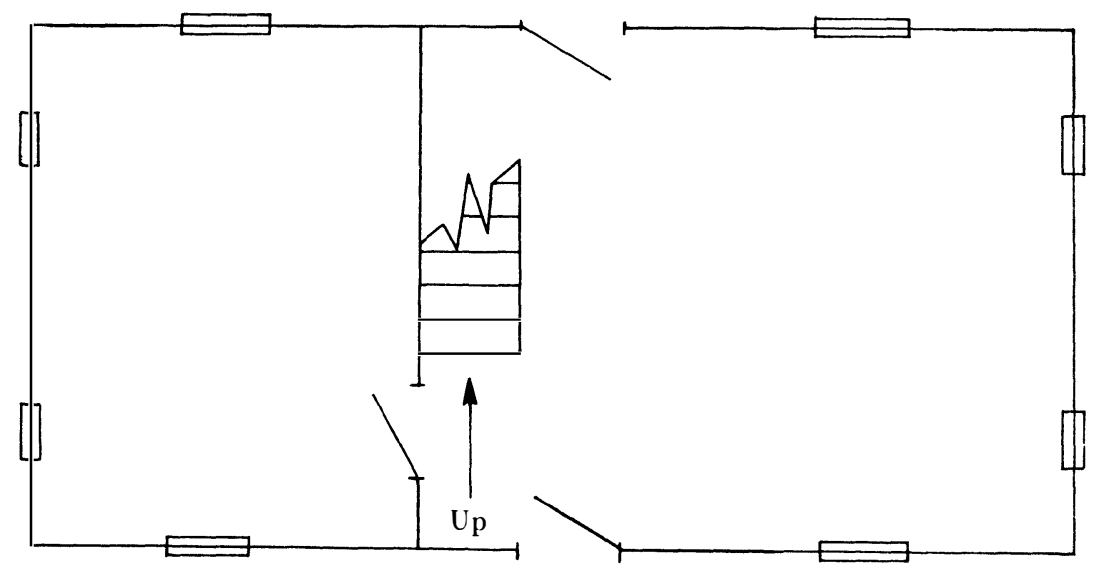


cannot look in unless they are very close. It is thus impossible for people on the porch to make contact with people outside without shouting out, and even then someone on the road must turn aside and enter the porch to make two-way contact. Part of the virtue of an open porch is that one can exchange a wave or a brief greeting with someone on the road without making any special effort. Most people who have screened their porches lament the loss of openness, and a few of them, men in particular, now sit out in the yard in order to recapture the old feeling of openness.

Because the family histories and fortunes of the occupants are so intimately linked to a house's architecture and its structural changes, I rehearse the development of one old home place. This narrative should make it abundantly clear that a period 1 house is a living, changing structure and not a static object. The large house of today may have started life as a one-room cabin, and in no case is what one sees today the result of a single period of building. My main aesthetic point is that the people of Tidewater do not treat architectural space as a fixed quality of an old house. They feel free to manipulate it as they wish or as technological advances create new choices.

The house I consider in this exercise was built in 1868 by Cull Kinsey and added on to, up and out, by him and by later generations. Cull started by building two rooms side by side with a breezeway down the center. As you entered the house through the breezeway, you could turn left into the bedroom or right into the general-purpose room, used for cooking, eating, working, sitting, or whatever (Figure 4). As his family grew, Cull partitioned the bedroom into two bedrooms and then built a lean-to addition, for use as a bedroom, to the right of the general-purpose room. To complete the change he built a porch that ran the length of the building (Figure 5).

Cull's son Paul built upward. He added a second story above the original portion of the house, making this floor into two large bedrooms, the size of the two old rooms downstairs. Downstairs he removed the partition wall between the two bedrooms and used the room as a sitting and work room, reserving the kitchen space for domestic tasks. Eventually he built a separate kitchen at the back of the house to keep the heat of summer cooking away from the main living space. Paul had only two children, and when the elder left home he began to take in boarders. To separate his family from the guests he built a dining room adjacent to the kitchen building and set aside the left-hand main room as a guest sitting room (Figures 6-7).

Paul's younger child Mary also had two children. Most of her life 
Figure 4. Kinsey house original plan

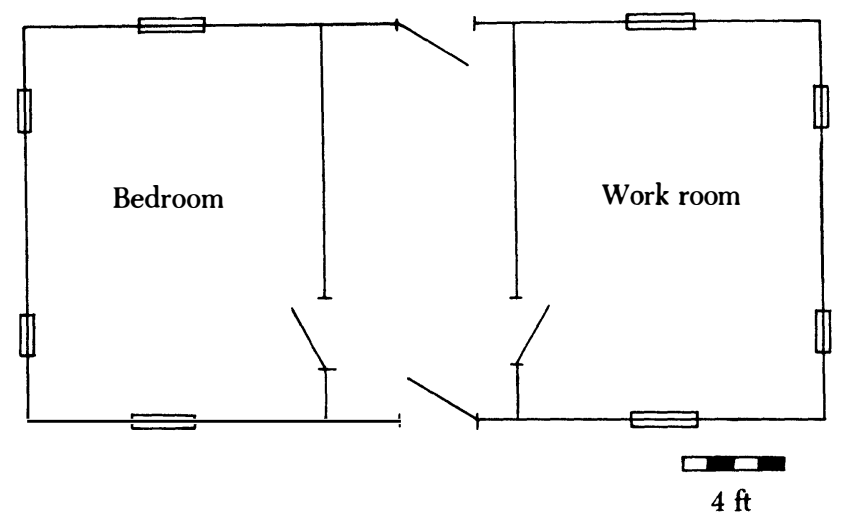

Figure 5. Kinsey house first modification

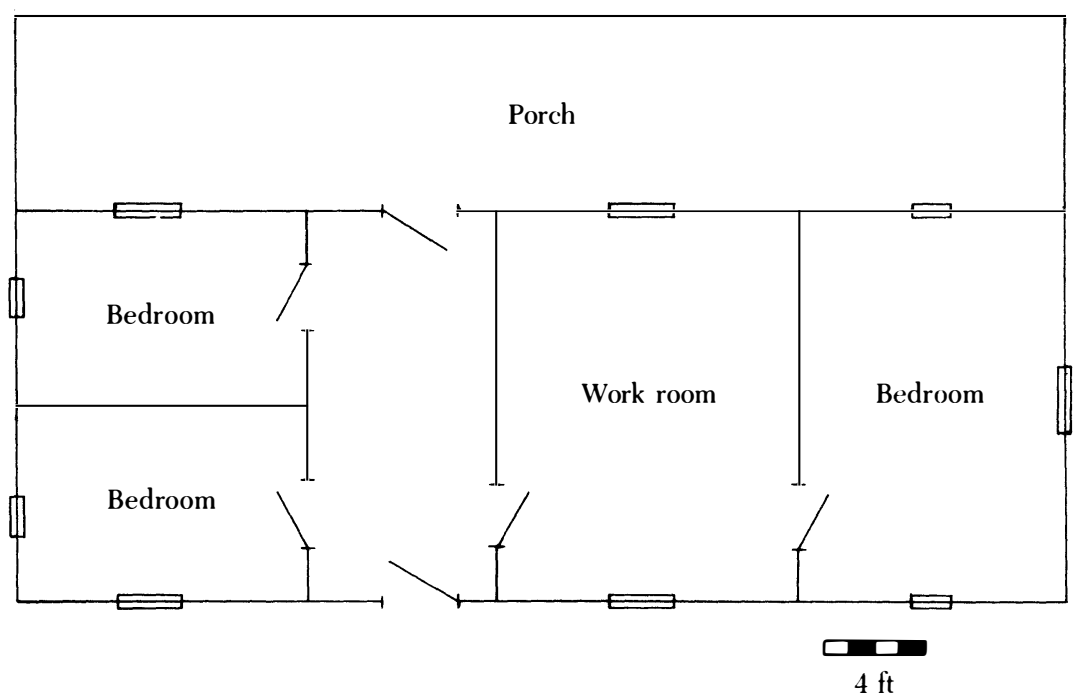

she had looked after the guests with her mother, so she simply continued existing practice when she inherited the house. In the 1930s, when electricity and running water became available in the county, Mary could not take immediate advantage of the opportunity because it necessitated major structural changes. Before long, however, she 
Lord I'm Coming Home

Figure 6. Kinsey house second modification, upstairs

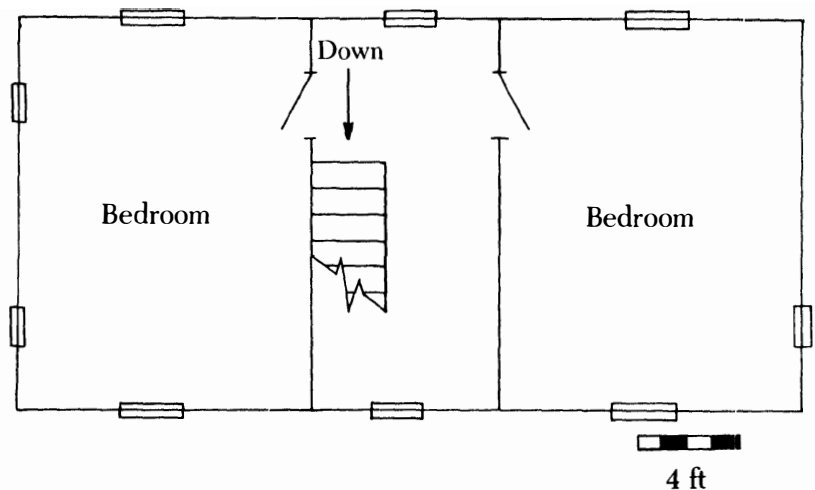

Figure 7. Kinsey house second modification, downstairs

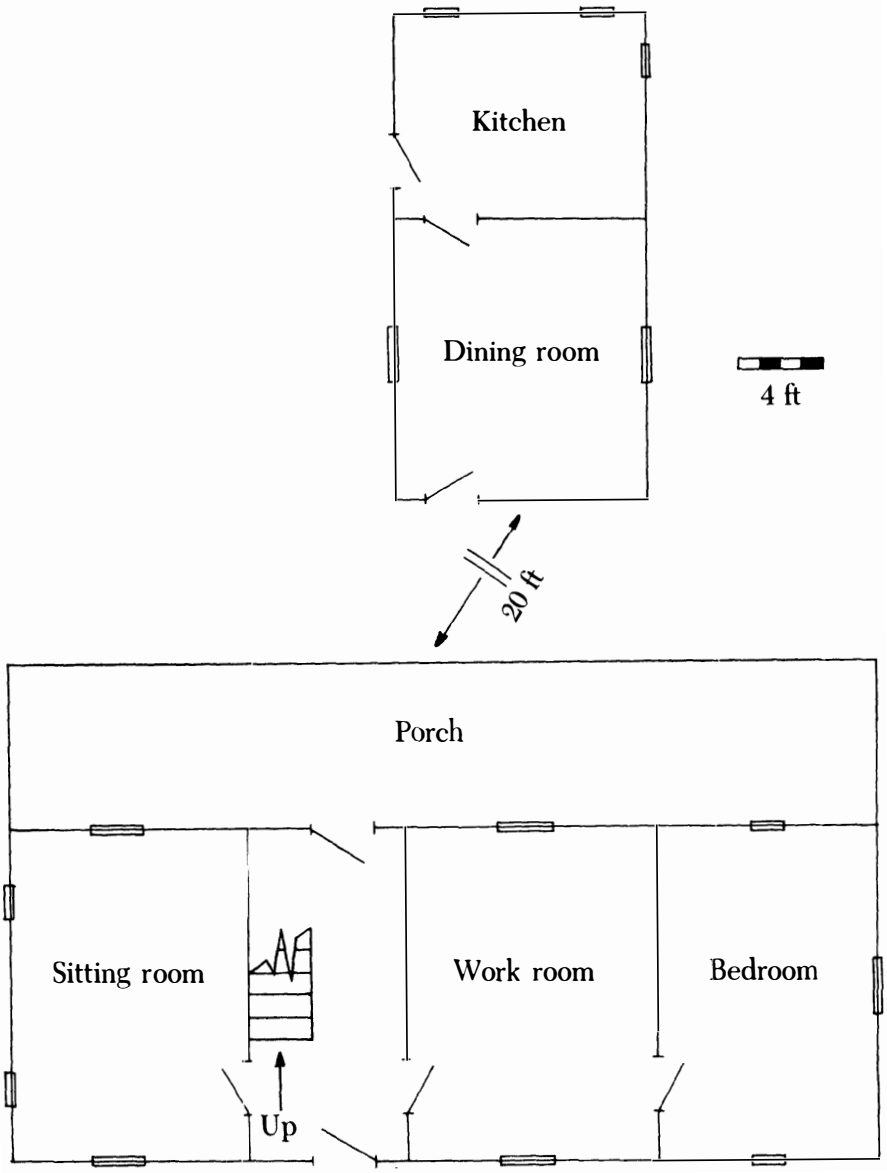

[52] 
Figure 8. Kinsey house third modification, downstairs

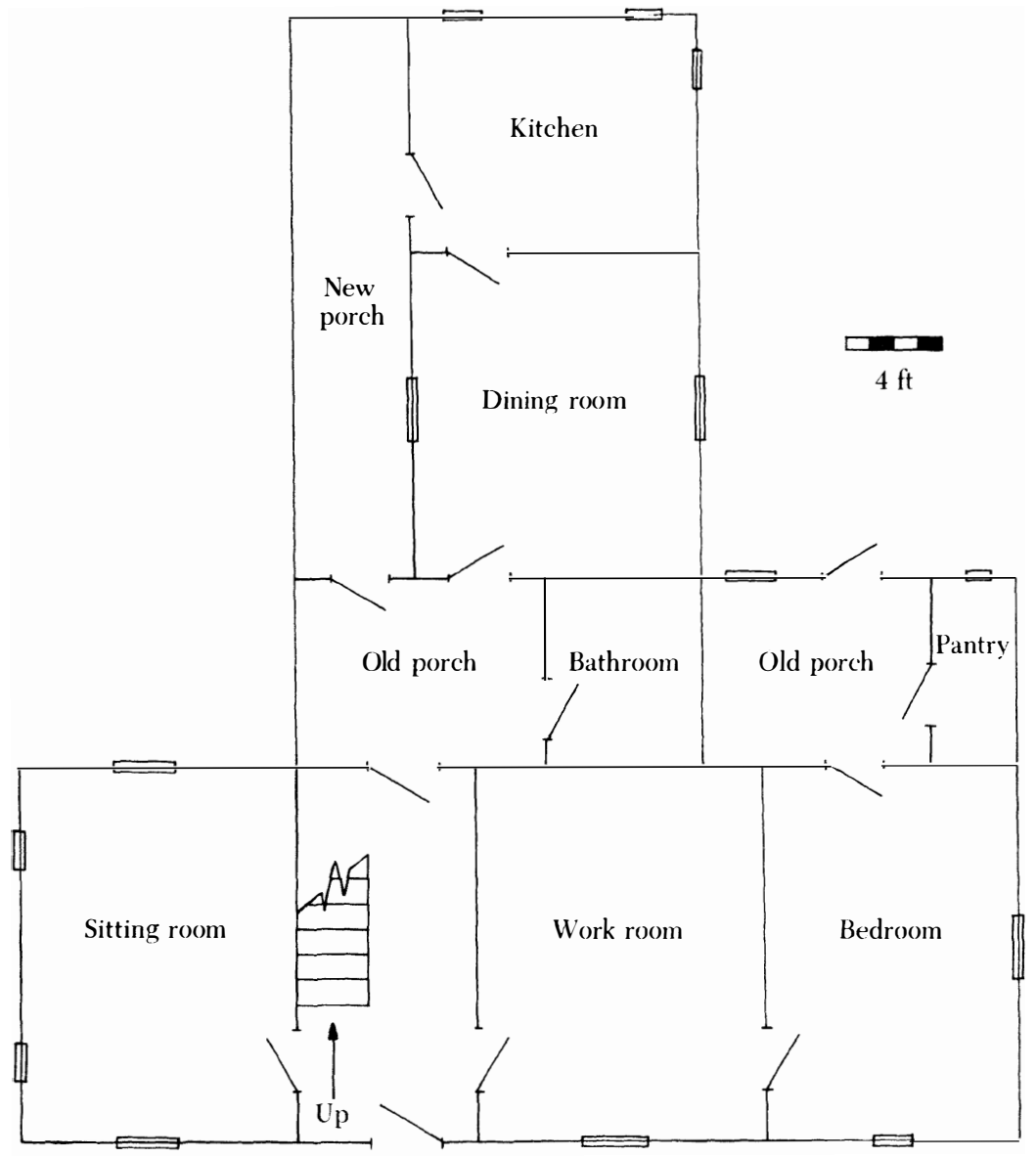

had saved enough money to have the kitchen and dining room moved, forming a tee at the back of the house butted up against the old porch. She had the whole extension, including the porch, roofed continuously. The old porch, which was shortened somewhat, became a bathroom and washhouse, and the adjacent kitchen and dining room extension now had electricity and running water. The outbuildings had to be moved beside the house to limit plumbing and wiring for kitchen and bathroom facilities. To make up for the lost porch she had a new one built on the kitchen and dining room tee, forming a walkway into the main house (Figure 8).

In the 1950s Mary grew tired of the arrangement of the downstairs 
Figure 9. Kinsey house fourth modification, downstairs

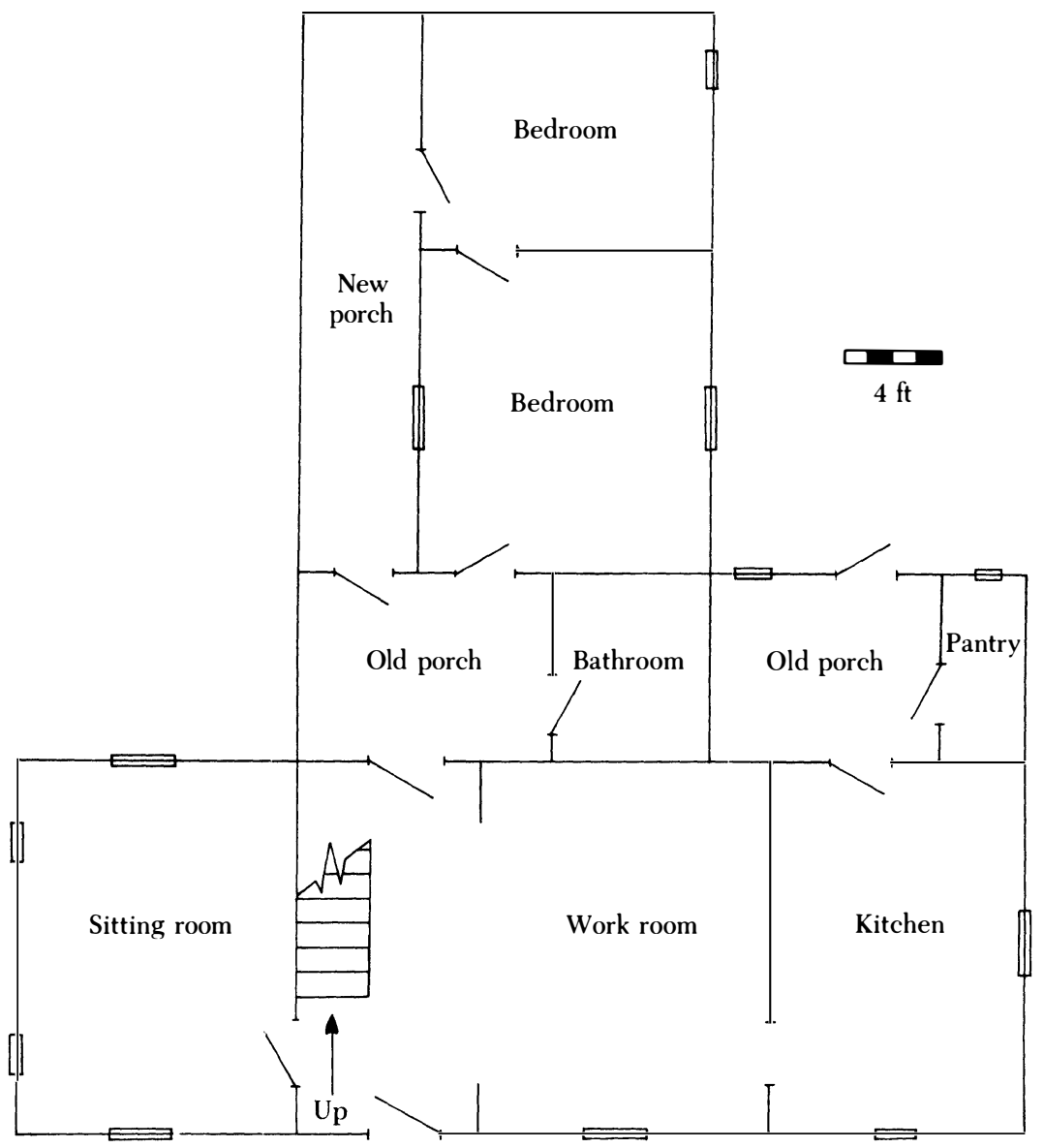

and determined on a complete overhaul. She converted the lean-to bedroom into the kitchen and made guest bedrooms of the dining room and the old kitchen. She took out the righthand breezeway wall to enlarge the center room, which served as a spacious congregating place for dining, bridge parties, dancing, and so on. Now people entering from the road walked directly into the main room instead of a narrow passage. She also screened in the new back porch (Figure 9). Since then the house has remained the same. Her husband died not long after the changes were made, and she has now lost interest in home alterations.

This continual reshaping of the architectural space is a characteristic 
Figure 10. Period 2 house
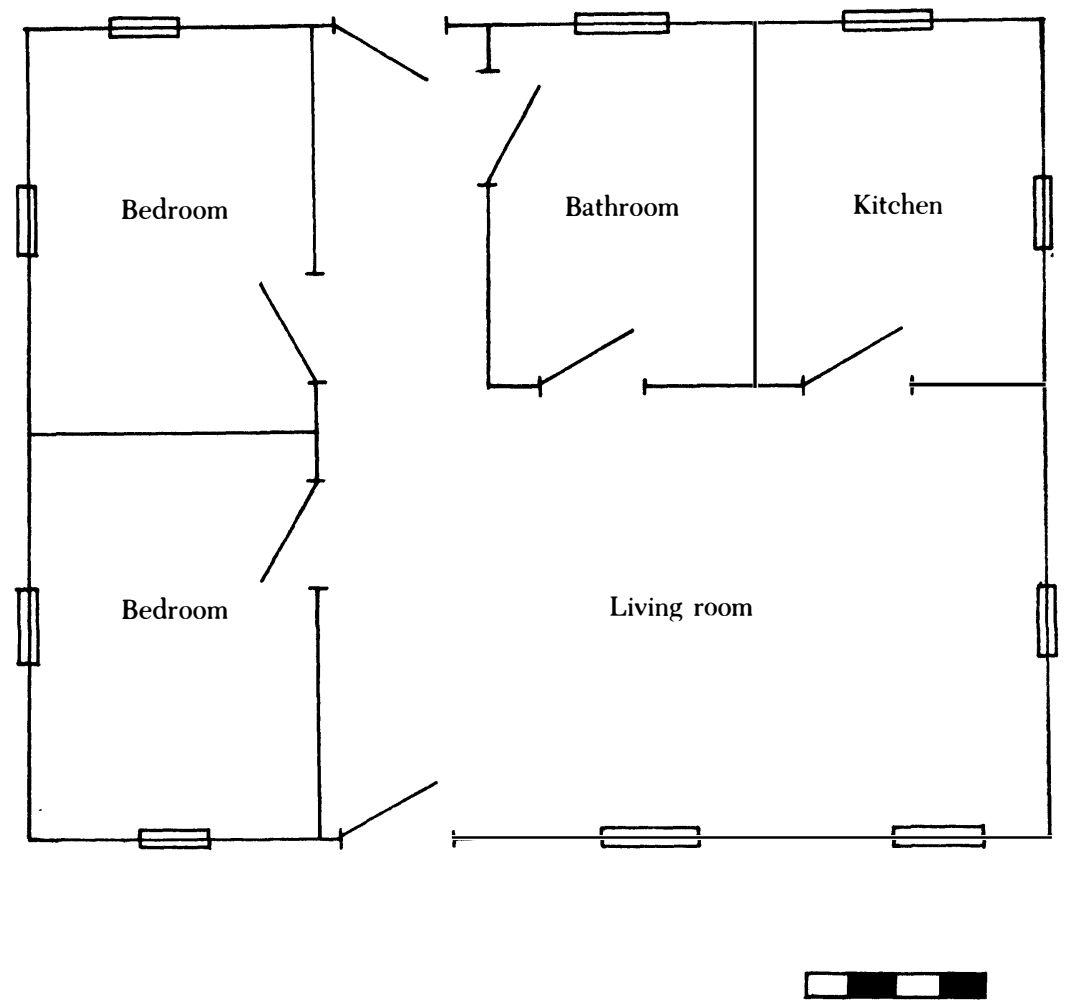

$4 \mathrm{ft}$

of period 1 houses only. As a result, inheriting the old home place brings with it aesthetic possibilities and responsibilities. Whoever lives in such a house takes over a never-ending task of molding and modifying space.

The houses of period 2 are generally one-story frame houses. The floor plans differ so widely from one another that few generalizations can be made. Some are classic hall-and-parlor type, others are arranged like shotgun houses; some have ell or tee appendages, others do not; some have front porches, others do not (see Figures 10 and 11). Two general points can be made. First, this beginning of structural diversity is a symptom of increasing concourse with the larger world. Most of these houses were built from architect's plans, whereas most period 1 houses were not. Second, all of these houses were cheap to build and are smaller than period 1 houses. Few have been structurally altered since they were constructed. Although they vary in 
Figure 11. Period 2 house
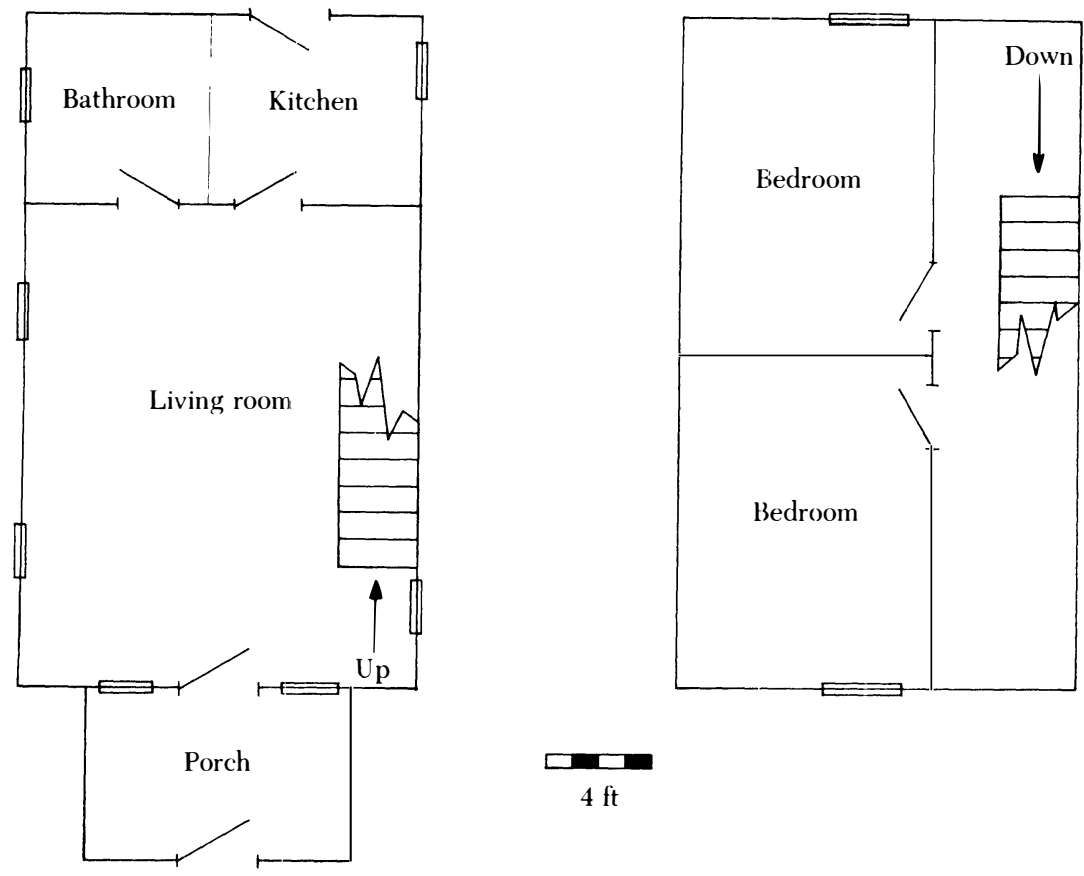

plan, they were built at a time when the order of the day was maximum utility for minimum cost. Present occupants agree that little can be done structurally to use internal space better. Also, owners are reluctant to pay for changes to a house that does not have a high market value. Most of the houses of period 2 were built to accommodate the offspring of large families who could not all inherit the family house but did not wish to move away. By the 1930s a road system gave easy access to a wide area; it was feasible to live in Tidewater and work elsewhere.

After this somewhat mixed period two trends emerged. Long-term residents and old families of Tidewater began building large brick dwellings, whereas newer residents moved into mobile homes. The floor plans of the brick houses, show great variation, and all of these houses are architect-designed. They are basically frame houses on a concrete foundation with a brick-veneered exterior. Most of them are much larger than anything previously built in town; not only do they have more rooms than the older houses, but the rooms themselves are bigger. All are built on one level or are split-level, so that they present 
Figure 12. Period 3 brick house

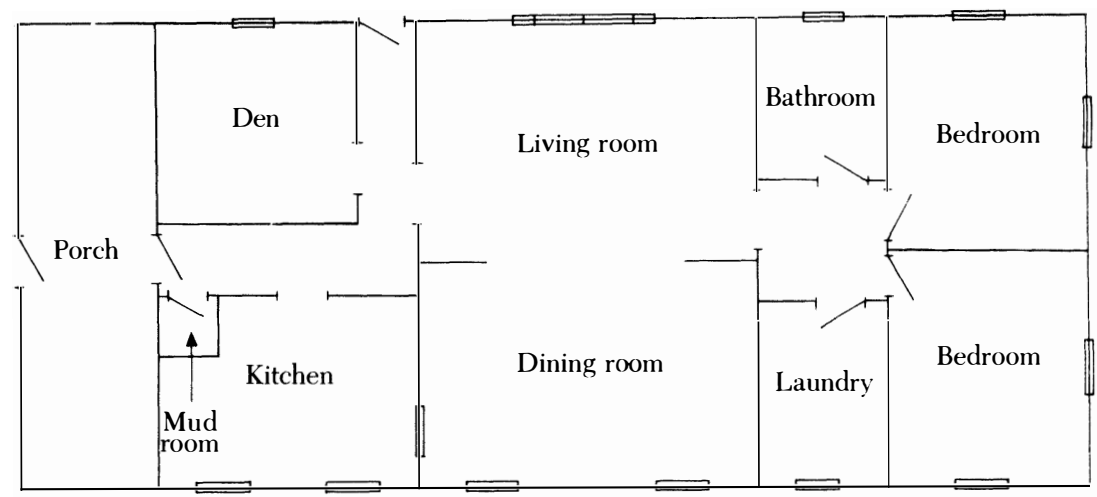

$4 \mathrm{ft}$

Figure 13. Period 3 split-level brick house

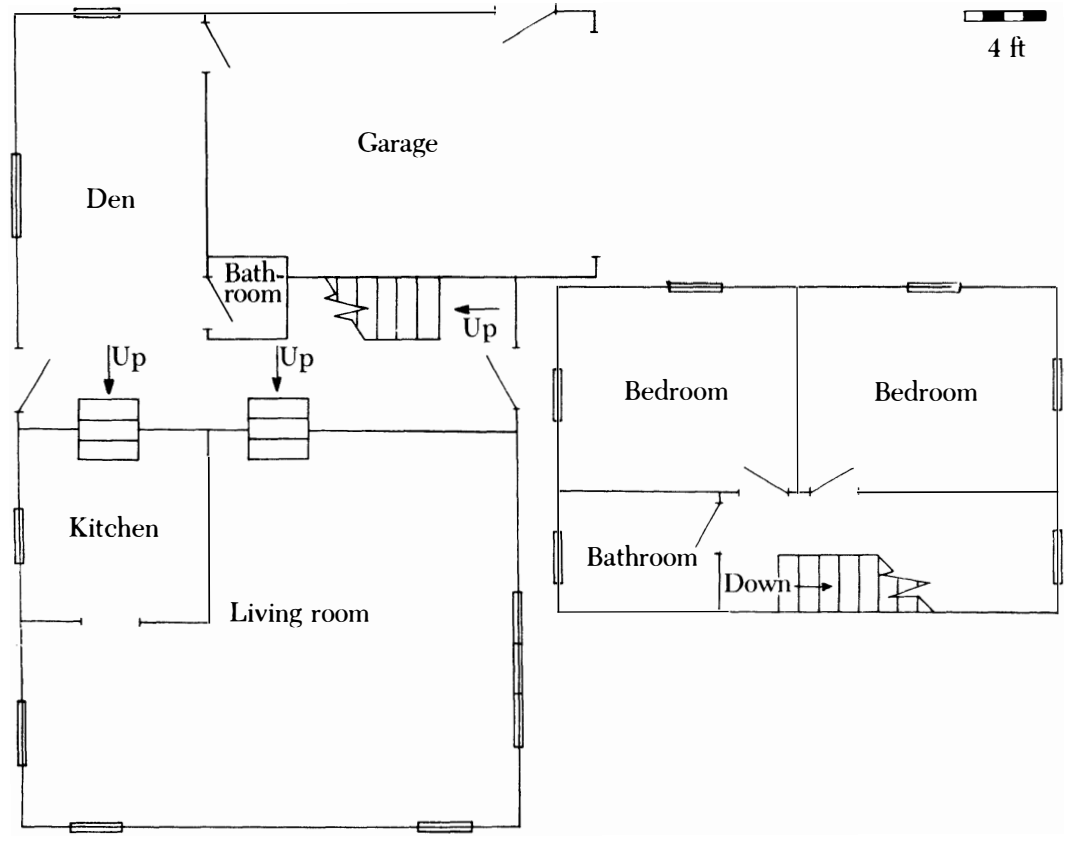

a much broader profile than any of the older houses (see Figures 12 and 13).

The second trend is diametrically opposed to the first. In the last few decades some members of older families have turned farmland 
into commercial trailer parks. For the most part newcomers and younger married couples live in mobile homes. Newcomers live in the commercial parks, members of older families locate their trailers on small corners of farmland. In contrast to the brick houses, mobile homes are cheap, small, and have a stereotypical floor plan.

A few houses do not fit into this general schema. A small number of houses on the periphery of Tidewater have been built by newcomers to the region since the 1950s. One has a kind of Spanish/Southwestern adobe appearance, another is reminiscent of an A-frame chalet. Most local residents of Tidewater describe these houses as odd or unappealing. This aesthetic judgment is noteworthy because they never express positive aesthetic feelings about house exteriors. Positive comments are reserved exclusively for interiors.

I reserve most of my specific comments on houses until I have examined decor, but one point should be borne in mind. Classification by house type tends to simplify and to smooth out diversity. Few houses in Tidewater look similar, however, and even those that have underlying structural similarities are superficially different. Those that are not brick are sheathed in a variety of materials, clapboard, shingle, and metal siding predominating. Generally siding is preferred because it requires no maintenance and yet always looks neat. Clapboard is least desirable because it needs constant attention. Most clapboard houses have been sheathed in siding over the past twenty years. In the past it was customary to paint houses white and pick out a few trim details in a dark color, and many houses still follow this pattern even where siding replaces clapboard. But a significant minority are now painted in darker colors, dark green being slightly preferred. Finally, all houses differ as to external ornamentation. Some have carved porch rails or gingerbread in the gable ends, but such details are not especially common, and many houses have none. The combination of sheathing material, colors, and ornamental features makes each house look different despite structural similarities.

In Tidewater there is both explicit and tacit agreement that the interior of the house is the woman's domain and that the exterior, the yard, and all of the buildings in the yard are the man's domain. Tasks are conventionally divided not so much on the basis of what the task is as where it will be performed. For example, women paint the interiors of houses, men paint the exteriors; women cook inside, men outside; and so on. Of course it is easy to find exceptions: men repair faulty plumbing indoors, and women hang the washing outside to dry. Perhaps the domains should be seen as somewhat overlapping or shading into one another. 
This conscious split in domains is manifested in daily behavior. Women spend most of their time inside the house, and men outside. The men of Tidewater have social and traditional reasons for spending their days outside the house, but there are definite disadvantages as far as personal comfort is concerned. For example, one waterman, a great ox of a man who is generally admired for his staunch adherence to traditional values, is almost always to be found, when not working or sleeping, in his backyard. Even though his house is fully airconditioned and centrally heated, he will not seek refuge from the elements indoors. On a hot humid day in August he can be found sitting under a shade tree, swatting flies and chewing tobacco. On one occasion his wife held an afternoon party for one of his female relatives, and he was obliged to attend out of kin loyalty. Even though it was close to one hundred degrees in the shade outside and airconditioned inside, he complained throughout the party that he was hot and left periodically to sit outside. As soon as he felt his loyalty to kin had been served, he left permanently.

When sex roles are reversed, there is inevitable comment. Women hunters, though very uncommon, do exist and are considered either mannish, if they are good, or a nuisance, if they are not good. Interestingly, women who are bad hunters evoke far less comment than good ones. A married man who helps in the family cooking may also evoke adverse criticism or become the butt of jokes. On several occasions I helped an infirm woman by transferring prepared foods from her work table to pots on the stove, which produced considerable joking among her friends. Furthermore, men who become tied to the house, as in the case of disability, lose influence in the men's world. The home is not without prestige and influence; quite the opposite, as this chapter demonstrates. But it is the woman's influence that resides in the house, not the man's.

Very few houses in Tidewater have a room especially furnished as a formal sitting room (as distinct from a family room). This absence is unusual for the South. In Tidewater one room serves as both formal sitting room and family room, with the degree of formality of the decor varying according to the desires of the woman of the house. These rooms run the gamut from spotless, elaborately planned spaces set with antiques to random assortments of styles of furniture in various stages of disarray. Most, however, lie somewhere in a middle range, that is, neat, comfortable, and generally organized without too many appointments of high monetary value. In appropriate weather, and at appropriate times of day, all guests-whether old family friends or strangers, whether of high or low status - are welcomed in the family 
room. This style of living is found in all house types and therefore serves as a general indication of the needs and cares of modern residents. Tidewater people represent themselves to outsiders as friendly. A sign on the highway at the edge of town advises motorists that the local church is "a friendly church in a friendly town." By the same token a visitor should not be held at bay in the prim formality of a sitting room but accepted into the heart of family activity. Also, Tidewater women cannot abide devoting a major portion of the house to a highly specialized function such as formal entertaining.

Aesthetic judgments about house interiors were easy to elicit from women, who couched them in terms readily identifiable as aesthetic. Samples include "the most beautiful house in Tidewater," "pretty, but hard to keep clean," and "very attractive." Those houses generally considered attractive or beautiful differ from one another both structurally and decoratively. Admittedly, most of these houses are the newer brick ones, and one might be tempted to think their very newness predisposes people to view them favorably. But in Tidewater "new" does not signify "good" as it does in many subcultures in the United States. The expression "new-fangled" is used for a wide variety of modern inventions and is derogatory. Newness by itself is not sufficient for the brick houses to be called "attractive."

Attractive houses have in common what might be called a thematic unity of decor. In each the rooms open to general inspection are decorated in an identifiable style. One is entirely furnished with flawless antiques, another with furniture that was in vogue in the 1940s, a third with modern reproductions of older pieces, and so on. Each room in these houses looks deliberately planned and laid out, whereas rooms in other houses are more of a mixture of accumulated pieces in different styles.

Whatever notions might be held of beauty in house decor, there is often a correlation between aspects of the occupants' lifestyle or pleasures and decor. Both the man's and the woman's concerns are represented, even though the interior is primarily the woman's domain. Thus, for example, the houses of keen hunters are often adorned with working guns, old guns, decoys, pictures of wildfowling, and the like. But the relationship between furnishings and personal concerns, particularly in older families, goes deeper. Many pieces evoke strong memories, have a story attached to them, or are stylistically similar to pieces from a cherished era.

One well-known raconteur and his wife have their house furnished in turn-of-the-century style, with a great number of marble-topped 
pieces. The few new pieces in the house are reproductions of this same style. Many of the lamps in the house are made from oil lamps salvaged from shipwrecks, and scattered about the house are objects from and mementos of old boats and water activities. The husband prides himself on the stories he can tell concerning events at the end of the nineteenth and beginning of the twentieth centuries, of shipwrecks, the Wright brothers, market hunting, and so on. His strong associations with this time are reinforced by the overall decor.

Another home, originally a plantation house and still owned and occupied by a female member of the family that built it, is furnished with inherited pieces of the same vintage as the house. Pictures of family members past and present adorn walls and table tops, and a few items associated with the legal profession are prominently displayed in remembrance of the current owner's late husband, a county judge for many years.

Generally speaking the houses occupied by the eldest scions of the oldest families, that is, period 1 houses, are filled with furnishings and decorations that have been accumulated over several generations. Each one has a kind of family style reflecting the common interests of many members of the family. The houses of the younger generations do not contain many inherited items, and if they are unified at all it is around modern furnishings. Most have only one or two older items inherited from a family member and cherished as a token.

The thematic unity of the furniture is often accented by items on display on walls and in cabinets. Some men and women are collectors and are proud to display their collections. One farmer collects projectile points that his plough turns up, another mounts the breast bones of birds. One woman collects flowers carved from ivory, a second has a cabinet filled with china replicas of swans. Also to be found are collections of guns, decoys, fishing lures, deer antlers, and all of the paraphernalia associated with water sports. It is common to find small pieces of handiwork such as cutwork, needlepoint, embroidery, and cross stitch on table and chest surfaces. These are more likely to be heirlooms than produced by the woman of the house, since needlework is declining in popularity.

There is also one common taboo in interior decorations: it is considered the height of bad taste to display things from the wild unless they have been fundamentally transformed. No one displays stuffed ducks or fish, even though the area is known for hunting and fishing and some guides practice taxidermy for the tourists. Taxidermy is deemed a "foreign" habit that violates a basic local premise of sporting: fish and 
game are for eating. One local hunter was given a stuffed wood duck as a birthday present by a tourist, and the gift left him in a quandary. He could not throw it out (which is what he and his wife wanted to do) because it was a present, but he did not want to display it. However, the tourist might arrive unexpectedly and ask where the duck was, so he could not bury it in the attic. His solution was to shift it around constantly, sometimes daily, trying to find a spot where it was "on display but out of sight," that is, where it could be seen if you cared to look for it but where it was not in regular view.

It is, however, appropriate to display artifactual treatments of the wild or objects that are employed in the struggle with the wild. China ducks or paintings of birds in flight are perfectly acceptable and relatively common. Photographs of hunters and fishermen with their spoils are rarer but not uncommon. Guns and other hunting paraphernalia frequently form prominently placed displays. In general, however, the outside world does not belong inside, and whatever comes from the outside must be transformed. Wildfowl and fish for cooking are not brought into a house until they have been prepared. Fowl are plucked, gutted, and feet and head are removed. Fish are at least gutted, scaled, and the head is removed, and they may also be fileted. These tasks are performed in the yard.

The clear distinction between inside and outside may be manifested in a clash of styles of decor. The exterior may give no evidence of the thematic unity of the interior. For example, several of the new brick houses are furnished with antiques. The owners delight in the surprise of newcomers when they enter these houses. Furthermore, it is virtually impossible to elicit aesthetic judgments about house exteriors from either men or women. The woman's lack of interest is understandable; as the exterior is neither her domain nor her concern (hence her delight when newcomers find the interior, her work, appealing after they have seen an exterior that is not her work). When a woman compliments another by saying she has a nice or pretty or attractive house, she is invariably referring to the interior and will qualify her remarks by mentioning some aspect of the decor or the furnishings. A man's reluctance to talk about the exterior, his realm, in aesthetic terms may simply reflect a general anti-aesthetic posture assumed by males. Basically, a house exterior "looks good" to man if it is trim and functional. Well-painted boards will not rot, and a wellplaced tree gives shade.

Details of the use of internal space and furnishings are examined below, but here it is instructive to show the layout and furniture plan 
of one house and give a general sense of how the woman who owns it uses the space. Figure 14 shows the furniture plan of the ground floor of the period 1 house whose building and additions were described above. Mary arises at about 7:00 A.M., dresses, and goes to the kitchen to make breakfast for herself and her daughter Libby, who is married and lives in a separate house that she and her husband had built on old family land soon after they were married. Her daughter arrives at about 7:30, and they eat breakfast together at the kitchen table. This meal usually consists of fried eggs and bacon or sausage with coffee, and it is quick to make and eat. Libby leaves to begin her own household chores at about 8:00.

Mary usually lingers over a second cup of coffee after her daughter

Figure 14. Furniture plan

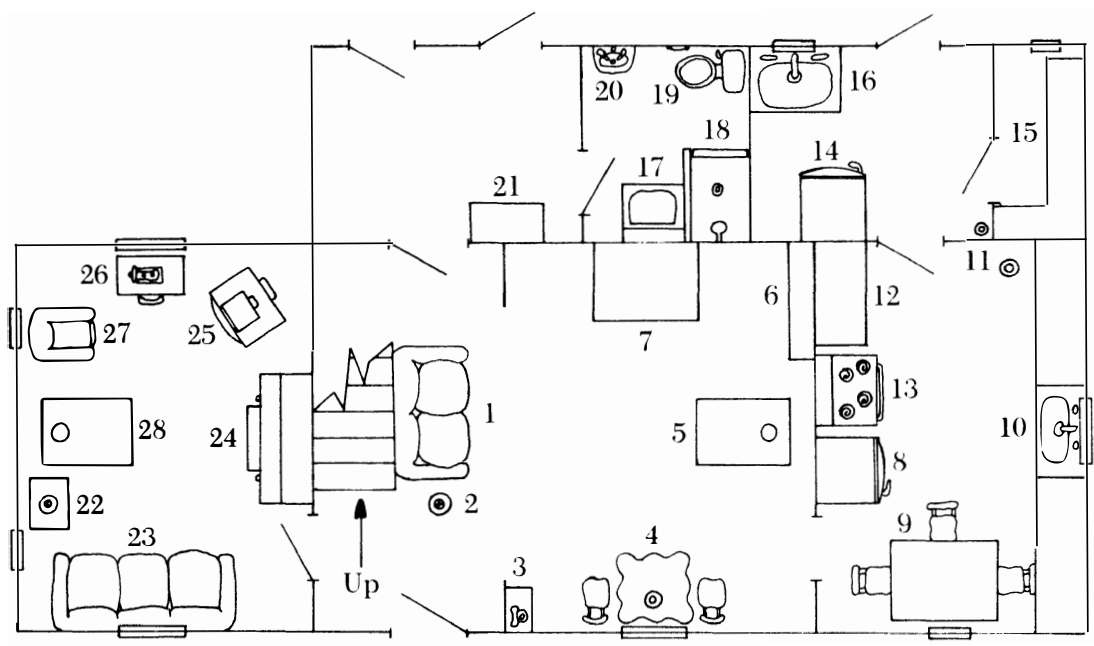

1. Sofa

15. Shelves

2. Floor lamp

3. Telephone table

16. Utility sink

17. Washer

4. Marble-topped table and chairs

18. Shower stall (lamp on table)

19. Commode

5. Oil-burning stove

20. Basin

6. Shelves

21. Quilt and blanket chest

7. Gate leg table (folded)

8. Refrigerator

22. Table with lamp

9. Table and chairs

23. Sofa

10. Sink and cabinets with counter top

24. Piano and bench

11. Dog and cat dishes

25. Two televisions

12. Table

26. Sewing table and chair

13. Electric stove

27. Recliner

14. Freezer

28. Oil-burning stove 
has left and plans her day's itinerary. Although she has a pretty regular weekly routine (washing on Monday, grocery shopping on Thursday...), things can crop up to throw her schedule off, such as a neighbor's illness or a change in the weather. By the early morning, though, she knows what she has to contend with and can plan accordingly. At this point she decides on the major chore of the day and plans the evening meal (so she can check supplies to see if she needs to run out to the general store for odds and ends before she begins preparations in mid-afternoon). Also, if she knows what she is to prepare, she can decide what to do with gifts of food when they show up, that is, whether to use them immediately in some way or to prepare them for saving.

Once she has made these decisions, Mary clears away the breakfast dishes and sets to work on the day's big chore. This may be vacuuming, washing, ironing, canning, and so on, and takes place in one of the many interior work spaces. Naturally, washing is done in the washroom, food storage in the kitchen. But most tasks that need a clear space Mary sets up in the middle room. She does her ironing here, for example, dries clothes by the stove on damp days, and cuts out cloth for dresses. Not only does the room give her space to spread out, with a big dining-room table to work on, but she can also see visitors immediately as they enter the front door (friends do not knock). If she wishes to take a spell or there is a natural pause in her work, she sits at the table by the window that commands a good view of the road. This room is pleasing to work in also because it is decorated with pieces of china she has collected over the years. Although she does not routinely stop and contemplate these pieces, her eye falls on one or another as from time to time she looks up from a task.

At midday she stops to prepare a quick lunch, usually consisting of leftovers from the previous night's meal. Often this preparation entails little more than setting dishes from the refrigerator on the kitchen table and selecting a plateful from them. After lunch she finishes her chore from the morning and then retires to her easy chair in the sitting room. Often she is working on a number of needlework projects, and she may work on these until around 3 P.M. when it is time to start the evening meal. Throughout this time people may stop by, always with a specific purpose but also willing to chat for a while. Mary entertains her visitors wherever she is and does not usually stop what she is doing to talk. Nor does the status of the visitor matter. If the preacher calls while she is peeling potatoes, she asks him to sit at the kitchen table with her and lets him conduct his business while she continues her job. Every downstairs room is equally appropriate for guests. 
Mary plans the evening meal for 6 P.M. to coincide with her sonin-law's return from work. She begins preparations at about three o'clock, and soon her daughter shows up to assist. They both sit at the table to get the raw ingredients ready, with Mary supervising all operations and doing the actual cooking. When Libby's husband finishes work he goes straight to Mary's house for dinner, and all three sit down at the kitchen table together. After dinner Libby clears away the dishes and then goes home with her husband. Mary spends the remainder of the evening in the sitting room, continuing her needlework or watching the television, or both. In the past she would not have watched television or listened to the radio without doing some handcraft at the same time, but here eyesight is failing and she now finds it hard to do both.

Architectural space and furnishings, it is clear, work together to create different internal environments, each with its own feeling. Partly because of custom and usage, partly because of general layout, Mary feels differently about each of the spaces in her house and chooses the space appropriate to her needs or her mood. These feelings can be augmented by the different ways that rooms confine the air and the resultant aesthetic effects. The central room has the breezeway in it, and so air is constantly cycled through, whereas the sitting room and kitchen have relatively still air. The air in the central room is clean-smelling and invigorating, and rather cooler than in the other two rooms.

The air in the kitchen is always hot and humid. Most meals involve the long, slow boiling of one or more green vegetables, creating a steamy atmosphere in which the general smells of cooking linger. Over time kitchens can take on the permanent smell of cooked greens because the cooking steam clings to walls and surfaces, imparting a kind of seasoning to them. Older houses are particularly susceptible to this effect. The air in the sitting room is also still, and warmer than in the middle room, creating a mildly soporific mood (enhanced by the darkness relative to the middle room). All of the seats in the sitting room are soft whereas most in the middle room are hard, and so Mary's general pace is slower in the former than in the latter.

The internal spaces of the houses of Tidewater are organized by constellations of aesthetic forms. The dimensions of the space itself, decor and furniture, the texture of surfaces to sit on, the air quality and associated aromas-all combine to create units of space that affect the occupant differently.

The gardens and immediate environs of Tidewater houses are not ornate, and the town has few avid ornamental gardeners. This is not to 
say the residents tolerate unkempt surrounds to their houses, but they do prefer plainer landscapes. Because of the uniform flatness of the land no gardens have any contour, and most of the deliberate planting does little to alleviate this flatness. Generally houses are surrounded by lawn, with foundation plantings of evergreens or perennial flowering shrubs. Few houses are shrouded in trees, but most have a few trees strategically placed to provide shade. Most are ornamental, fruit, or nut trees. All of the yards of Tidewater require a minimum of care to keep them looking neat. Few people plant annuals or any kind of flower that takes more than the most perfunctory tending, so that yards are not highlighted by flower beds (see Figures 15 and 16).

Care of the yard is primarily the responsibility of the males in the households. For them, as far as the garden is concerned, the pragmatic outweighs the aesthetic. They frown upon spending too much time and money on a decorative aspect of the house's exterior, yet they do not wish their yards to appear uncultivated or untidy. They compromise with plantings that are easy to keep well-groomed without much effort. Only one man showed overt satisfaction in collecting and planting varieties of flowers, and he was considered an oddity, his behavior only partially excused because he had married into an old, local family from an equally respectable but slightly eccentric one from an adjacent county. His garden stands in absolute contrast to all of the others in town and is the source as much of amusement and bewilderment as of aesthetic pleasure. Even his wife tells stories of times he would ride to Virginia for a particular item but return with flower plants instead of what he had gone out for. In this and many other domestic matters he was considered unusual.

Those men who spend time in their gardens mostly tend vegetable patches. Yet even this activity is declining in popularity somewhat and now concerns perhaps a dozen older men. Their vegetable gardens are large, some over an acre, and the gardeners usually grow enough to take care of their own annual needs with a surplus for distribution to relatives and friends. Wives pickle or can much of the summer surplus, particularly tomatoes, beans, corn, and cucumber, for winter use.

In the very center of Tidewater the gardens of adjacent houses are contiguous. A scant quarter-mile from the center the farmland begins, sometimes behind the houses but mostly between them. Where farms are situated between houses, lawns and foundation plantings mark the homesites as clearly separate. The majority of the older houses have family burying plots on the grounds beyond the boundaries of the 
Figure 15. Yard plan, period 2 house

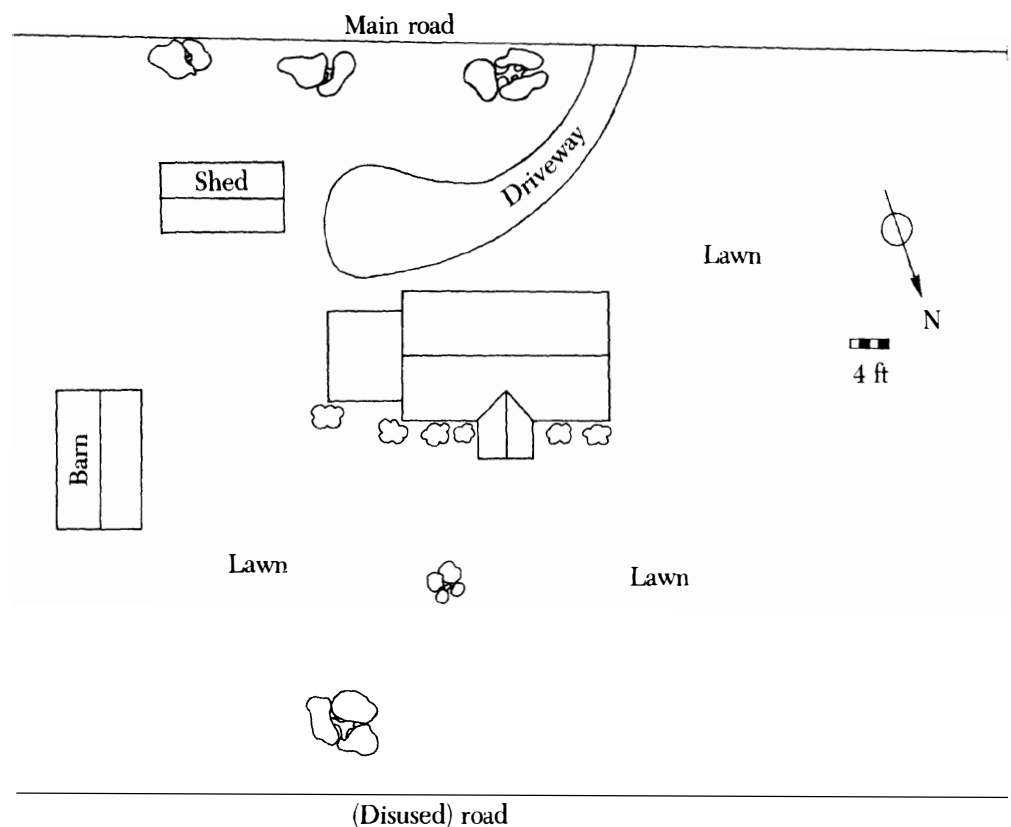

Figure 16. Yard plan, period 3 house

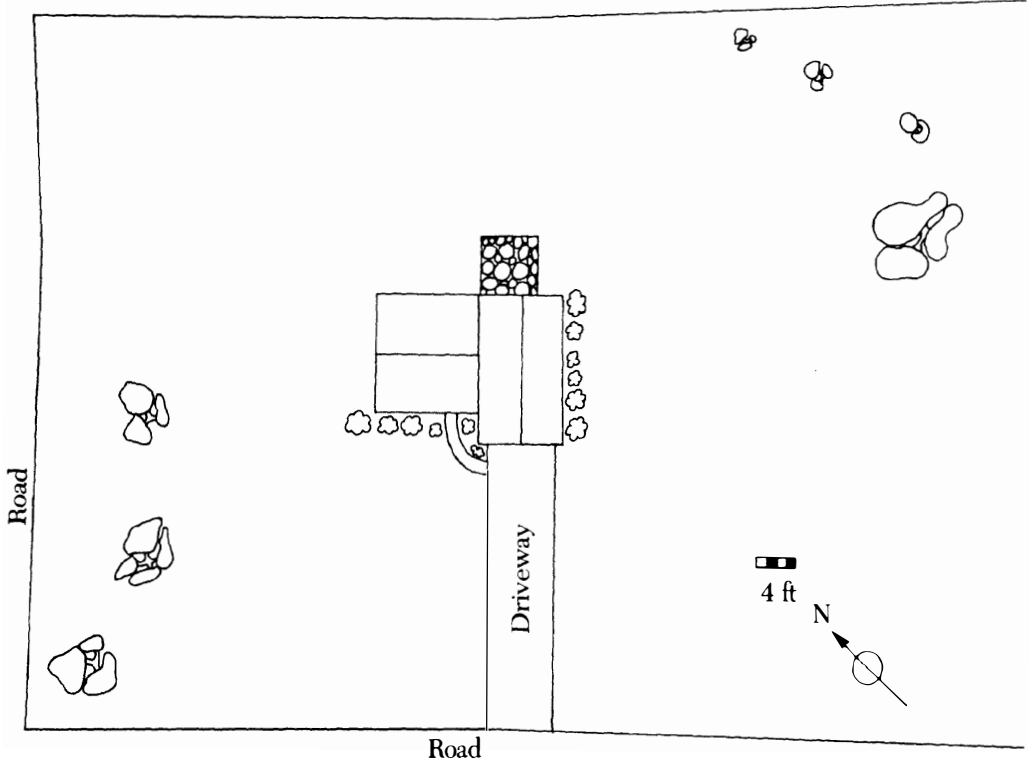


lawns. Dead forebears are located away from the innermost sphere of household lands, the cultivated garden, but they remain on the land they owned instead of being totally alienated from it in death. It is considered a vital part of annual gardening chores to keep the burial plots "cleaned up." This work entails cutting back briers and weeds and trimming edges. The graves are marked with simple headstones and are not otherwise decorated.

A close association between food production, including garden produce, and food consumption affects the aesthetics of food in the home. Some local women suggested to me that many people in Tidewater do not ordinarily consider food to be part of the aesthetic realm. Many locals ate the same things from week to week, they said, and rarely experimented with new dishes or ate at restaurants, except those that serve standard Southern family food. Empirically, this judgment is a little too clear-cut. It is true that by comparison a few families stand out as much more concerned with the aesthetics of a variety of foods than others. But even those people who are considered unadventurous have greater variety in their diet than might first appear, and they clearly make aesthetic judgments.

The passage of the seasons has a great effect on daily meals. Comparatively few men grow vegetables, but between them they supply a large number of households. Also, many nearby roadside produce stands sell locally grown vegetables. These vegetables are always preferred over those sold in supermarkets, and so local cooks still prepare produce as it comes into season. Moreover, some vegetables that are especially savored, such as black peas (not to be confused with blackeyed peas, which are also a favorite), are not part of the national produce market. They have to be grown locally and can be eaten only in season.

A seasonal aspect survives in meat consumption also, but now because of cultural conservatism more than ecological necessity. The practice of keeping livestock for household needs has dwindled to negligible proportions over the past two decades. Whereas in the past most households raised a pig and a few chickens to provide ham, salt pork, and bacon over the winter months and eggs throughout the year, residents now consider it more convenient to buy these items at the stores.

Men who grow vegetables always give away part of their crop, and fisherman and hunters regularly share what they have. Nor are gifts of food limited to raw ingredients. Women send gifts of cooked food to kin and friends, especially if the principal cook of the house is ill or 
indisposed. Gifts may vary from a full meal to a mess of greens. When a member of the community dies, friends prepare a meal at the deceased's house on the day of the funeral. The meal centers around a boiled ham bought by contribution. The presentation of food for the sick or bereaved from a friend's kitchen is considered "neighborly" and is perceived as an important act on the part of every established member of the community. Food gifts will most often be forthcoming even when rivalries exist between households, because "neighborliness" transcends most social dissension.

It is also considered neighborly to invite people to eat at one's table if they are visiting near mealtime and do not obviously have a meal to go to elsewhere. Many older cooks prepare meals that can be stretched to accommodate an extra person or two, and some cooks, considered miserly in other respects, are unfailingly generous with their hospitality at the meal table. Such generosity may derive in part from the fact that Tidewater has always been a food-producing community, and so food is a direct product of one's labor and not something bought with money. As the following stories attest, it is possible to be "poor," that is, have little ready money, but eat very well:

For Sunday dinner a lot of times we'd have about fifteen, twenty come to dinner, and we'd have to put two tables together, and all that. And in those days I thought, "Oh my Lord, I've never seen so many dishes in my life." My mamma would have a great big roast of beef, like the old rump roast, and cut up. And then fried chicken, and corn pudding, and stewed tomatoes, and all that stuff. We were poor but always had something good to eat.

My granddaddy ran a country store, and when it came lunch time he closed the store. The store was sitting out by the road and the house was set back. And whoever was in there, he invited them to lunch. And so they never knew how many they were cooking for. It was sorta like a hotel. It was in the thirties when we were growing up. We were poor but so was everybody else. We lived in the country and grew just about everything we ate.

Although Tidewater households are nuclear families, a family meal is not cooked in each home every night. Rather, one family cook, usually the eldest woman, cooks for the extended family. The core of this family grouping is matrilineal: men and children eat at the houses of their wives' mothers or wives' aunts. Many older women told me they did not learn how to cook until after their mothers had died. Such 
behavior not only maintains intergenerational ties among women but also relieves the financial burden and workload of young married couples.

A woman's mother's way of cooking tends to form the aesthetic standard by which the woman judges or describes her own:

You cook rabbit just about like you do squirrel. Salt and pepper it, and flour it, or not flour it. Now really and truly my mamma was the only one around here that didn't flour. She never cooked much with milk and it would be good. Most of us have to cook with milk to make it good. She could just use water, and her eggbread and all would be better than mine. But I'd have to put milk in mine. She could put no flour on her wildfowl and it would be good. Seem like mine would be better with flour on it.

Part of what made this woman's mother a good cook was her ability to make good food with fewer expensive (that is, store-bought) ingredients.

Each family cook is a node in a food-sharing network that is of primary importance in maintaining social bonds in the community. Men provide raw food in different ways: sport fishing and hunting, commercial fishing, gardening, farming, and so forth. Whether they produce food for their living or not, men always have surpluses of something or other. Each man is a regular provider for the family cook in the household where he eats, but he also takes food to other family cooks as he wishes. Generally these cooks are affinal or consanguineal kin to him or friends of his family cook.

These men sometimes give a cook more than she can use of some item, but she is not at liberty to redistribute portions in a raw or wild state. She must invest some of her own labor before the food is truly hers to give away. She may, for example, receive enough fish for two family meals, dress all of them and send half to a friend. If for some reason she knows she cannot dress all of the fish, she is bound to tell the giver to leave half with her and take half to her friend. She cannot accept the entire load and give away half of it undressed. Similarly, she might accept more greens than she can use, cook the whole pile, and send parcels out at dinner time.

Tidewater is a food-producing town, and the men enjoy sport hunting and fishing in addition to their work as farmers and fishermen. As a result, local diets potentially have great variety. Table 3 gives a reasonably complete list of meats that are available and considered generally pleasing. Not all people in Tidewater eat or enjoy all of these 
Table 3. "Edible" foods

\begin{tabular}{llll}
\hline \multicolumn{1}{c}{ Meat } & \multicolumn{1}{c}{ Poultry } & \multicolumn{1}{c}{ Fish } & Shellfish \\
\hline Beef/veal & Chicken & Spot & Crab \\
Pork/ham & Wild duck & Croaker & Oyster \\
Lamb/mutton & Canada goose & Speckled perch & Scallop \\
Deer & Snow goose & Bluefish & Shrimp \\
Squirrel & Coot & Drum & \\
Rabbit & Turkey & Flounder & \\
Frog & Dove & Mullet & \\
Turtle & Pigeon & Bream & \\
& Quail & Speckled trout & \\
& Blackbird & Rockfish & \\
& Woodcock & Panfish varieties & \\
& Snipe & & \\
\hline
\end{tabular}

foods, but most people eat most of them at some time during the year. Furthermore, these foods are generally considered "edible" even if personal tastes vary. Some older people do not like lamb, for example, but they do not consider others perverse for eating it. The length and diversity of the list is such that one would almost believe that Tidewater people eat everything that walks, crawls, or swims. But they are particular in their selections and will not eat a variety of foods available to them, even though they know they are relished by some people from outside the community. Table 4 gives a partial list of these foods. The reason given for not eating these foods is almost universally an aesthetic one. People say the meat is too "wild" or too "strong" for their tastes. Derision is heaped on people believed to eat these foods, who are cast as lacking taste or sense. For example, out-of-town fishermen, the constant butt of local humor, are scorned for eating the bass they catch. Tidewater men enjoy the sport of catching bass, but they

Table 4. "Inedible" foods

\begin{tabular}{llll}
\hline Meat & Poultry & \multicolumn{1}{c}{ Fish } & Shellfish \\
\hline Raccoon & Crow & Eel & Clams \\
Possum & Pheasant & Bass & Mussels \\
Muskrat & & Skate & Crayfish \\
Goat & & Pike & \\
& & Shad & \\
& & Raccoon perch & \\
& Catfish & \\
& & Carp & \\
\hline
\end{tabular}


throw all of their catch back. It is my impression that the people of Tidewater think that nonlocals who eat bass, skate, pheasant, and so on, have no ability to discriminate between the edible and the inedible. That is, they believe certain foods are intrinsically distasteful; anyone who eats and enjoys them must, therefore, lack powers of discrimination or necessary experience.

I used to have friends come down here from Durham, and they didn't know what really good fish was. They'd get these old bass, which we wouldn't even eat 'em, and we'd go down there and that's what they'd have. So I sent 'em some fish one day, I think they were spots or bluefish, and she said "now they're the best fish I ever had in my life." See she'd never really been accustomed to cooking good fish.

Naturally, agreement concerning what is and is not edible is not total. Some prefer saltwater, some freshwater fish, for example. And all have tried "inedible" foods at some point in their lives. One waterman told me he had eaten possum and enjoyed it-but, he added, he was "three sheets in the wind" at the time. I presume he meant the alcohol in his system had dulled his ability to act according to his customary aesthetic values.

The man who keeps an elaborate flower garden also runs athwart local opinion with his belief that no flesh is intrinsically undesirable, and he runs counter to local norms in taking a hand at cooking indoors when he wishes. He once conducted an experiment on his wife and daughter to demonstrate that "inedible" foods taste good. The two women were due to go on a long shopping expedition to Virginia, and he knew they would be very hungry when they returned. On the day before the expedition he bought a bushel of oysters and made a great show of shucking them that evening. After the women had left for Virginia, he went to a local pig farmer who was castrating young pigs and procured a batch of "mountain oysters" (that is, pigs' testicles). When his wife and daughter returned from Virginia he was at the stove frying "oysters." He offered them each a heaping plate, which they accepted and ate greedily. Only when they had finished did he tell them what they had eaten. He claims to have proved his point, but his wife and daughter will not eat mountain oysters again, even though they admit they enjoyed them.

On the other side of the coin, some foods are held in esteem in part because outsiders are believed to dislike them. Hog jowls, souse, chitterlings, head cheese, greasy greens, cornbread, and fat pork are all ammunition in the modern war between the North and the South. 
Yankees are chided for not liking these foods. Many of these items are difficult and expensive to obtain now, so they are no longer "po' food," but they are still sought out. Their contemporary value lies not in their cheapness but in their taste and in their value as markers that differentiate locals from outsiders. I have even known people in Tidewater to send packages of salted hogs' tails and feet to Northern acquaintances as a joke. The package is expected to bewilder and bemuse.

To an outsider the meat diet of Tidewater (quail one day, chicken gizzards the next) may appear an unusual blend of the exotic and the humble. But such adjectives are applied to these foods by people far removed from the land. For most Americans hunting is a rare sport, and therefore the products of hunting are rarities on the table. For the people of Tidewater hunting is commonplace, and its products are not treated as great delicacies. Goose, for example, is not served with the same exultance as it would be by, say, an Englishman. For the Englishman goose is a festive bird to be served only on special occasions. In Tidewater it is a commonly hunted bird served without pomp or ceremony. Indeed, in general game meats are accorded no unusual or extravagant care. Deer meat is cooked like cuts of beef, coot is jointed and fried like chicken, and duck and goose are plain baked. In fact, almost every time I asked a cook how she served a particular game animal, the description would include such phrases as "like fried chicken" or "like roast beef."

My husband's mamma made blackbird pie, you know the little old teeny birds. They were real fond of stewing birds and all. You made it just like you would a chicken pie. You made your pastry, or sometimes you'd make your pie crust, and stew those and put 'em in there. Then put another pie crust over it and bake it like that. And sometimes they'd stew it on top of the stove like a stewed chicken. You'd put your drop pastry in there like you roll out, like a flour dumpling, in there like that. So it was two ways you could do that.

One cook told me that in contrast to Northerners the women of Tidewater "overcook the meat and undercook the bread." They do not like meat to show any pinkness, and rare steak or beef is unthinkable. Northerners are said to eat "hard," that is, crusty, breads, whereas people in Tidewater prefer lightly cooked breads such as cornbread and spoon bread. Tidewater women also believe they eat breads more often and in greater variety than Northerners do.

These cooks also compare their tastes in cooking vegetables to those of Northerners. Green vegetables, both leafy and leguminous, are 
boiled for an hour or more with "seasoning," that is, fatback, salt pork, or hambone. Only the long cooking can impart the flavor of the seasoning meat to the vegetables. Also, many leafy vegetables, such as collards and mustard greens, require a solid boiling to tenderize them. Starchy foods, including potatoes and corn dumplings, may be cooked on top of the green vegetables. The seasoning meat is served along with the vegetable it has been cooked with.

Northerners are not the only "foreigners." Other Southerners may have different tastes and ideas as well:

My husband's brother's wife lives down in South Carolina. I had a recipe of hers, the way she cooked quail, and it's sorta a little bit different from us. They use wine and all like that. Most people around here don't do that, it's sorta new for them. And I really have never done it. And, oh my Lord, there are some recipes for ducks with marinades of soya bean sauce and all of that stuff. But I never have done that.

A regular evening meal does not end with a dessert. Desserts mark a meal as special. At the simplest level a meal can be special because it is someone's birthday. Then, to mark the occasion, the family cook bakes a birthday cake to be eaten for dessert. The main meal of the day on Sundays is traditionally more elaborate than those of weekdays and in addition to extra meats and vegetables may include one or more desserts. Most favored are pies (lemon meringue, chocolate chess, pecan) and cakes (sponge and pound in various flavors). There are also a few perennial but short-lived seasonal favorites, such as strawberry shortcake. A very elaborate meal, particularly at Christmas and Thanksgiving, involves several different desserts, mostly pies.

Of the several "special" meals throughout the year, by far the most elaborate is Thanksgiving. Some households have enormous family gatherings at Thanksgiving (greater than at regular meals where an extended family eats together), at which prodigious amounts of food are prepared and eaten. It is, of course, mandatory to have a turkey or two, frequently with an oyster dressing, and common to have other poultry besides. Duck-hunting season is split in two unequal segments, the first of which stretches from the Monday before to the Friday after Thanksgiving, and so it is common to have fresh wildfowl alongside the turkey. Accompaniments may include some or all of the following: corn pudding, sweet potatoes, "Irish" potatoes, cranberry sauce, candied yams, and cornbread. Desserts always include pumpkin pie and mincemeat pie but may also include chiffon, chess, pecan, 
and other regular favorites. In most houses the Christmas meal is like Thanksgiving's but often on a smaller scale.

At the other extreme the main meal of New Year's Day is deliberately sparse. It is a local superstition that "if you eat poor on New Year's you'll eat rich the rest of the year." In consequence everyone eats black-eyed peas seasoned with salt pork of some kind. Many people prefer salted hog jowls, but feet or ears serve the same purpose. Even though such a meal is symbolic of the direst poverty, it is eaten with gusto and delight.

I cannot end a description of local dietary habits without stressing the central role of the hog in cooking. One indication of the importance of the animal is linguistic. The word "meat" is used locally, as elsewhere, to refer to the edible tissue of land animals but more often to refer specifically to cured pork. If someone says "pass the meat" when a piece of beef and a lump of salt pork sit side by side on the table, the request is unambiguous.

Scarcely a single meal passes in which some part of the hog is not employed. Lard is the principal cooking fat, cured pork is the chief vegetable seasoning, rendered bacon fat is used as a sauce for salt fish, salt pork is an essential ingredient of the local version of Brunswick stew, and the many cuts of pork are treated to every kind of cooking process: frying, boiling, baking, roasting, stewing, smoking, salting, grilling, broiling, and drying. This variety reflects both the versatility of the hog as food and the fact that at one time hogs were raised everywhere.

Although few people now keep hogs, the local diet retains the usages of former times. What was once a largely pragmatic consideration has become an aesthetic choice. Even with the dramatic escalation in recent years of the price of traditional "po' foods," which has eradicated economic reasons for buying them, such foods are still purchased because they are perceived as essential elements in most meals. Some cooks periodically prepare po' food to evoke memories of the past. One, for example, made haslet stew at the end of every fall. This watery stew of pig's heart and liver, with flour dumplings, was formerly made at hog-killing time to use up perishable items quickly. The practical need to make the dish is gone, but the taste for it remains.

It is eating "poor" that provides the hallmarks of good cooking:

My husband's mamma was a lady that could take nothing and make something out of it. That's what I call a good cook. You would go to her 


\section{Lord I'm Coming Home}

table and think, "Well, we're not going to have much for supper." And, I pray, she would have a variety of things. And, you know, you thought,

"Well, we're not going to have much tonight." She'd have a little of this and a little of that, and it'd all be good. And she'd just mix it up good.

Some can do that.

The great majority of Tidewater women do not have paying jobs outside the home. A great deal of their time is spent in cooking and caring for household functions, and what they describe as "leisure" activity is also geared toward the domestic realm. Needlecrafts were once a popular pastime, and the products could be put to use around the house. Recently, however, younger women have not been learning these crafts from their mothers as they did in the past, and the skills are rapidly dying out. Whether a woman sews or not is now a marker of age.

Quilting was very common at one time, and many old quilts are carefully preserved as mementos of older generations of women. The women in town who still quilt are of the oldest generation, and none of their children has adopted the craft. Cutwork, embroidery, and other needlecrafts are now scarcely practiced, but products of previous eras are cherished. I begin with an analysis of quilts which is slightly more detailed and formal than what has gone before because the construction and use of quilts provide insights into the aesthetic realm of women and the home. Even though only the oldest generation quilts, the work embodies values that permeate all homes. Formal analysis is also necessary because many of the quilts I surveyed look to the casual observer as if they were simply thrown together anyhow. What may appear scrappy and uninteresting is in reality highly structured and informative of general aesthetic values.

A quilt may be a single object of appreciation, but many elements combine to produce the overall effect. Some quilt scholars have devised long lists of these variables for detailed comparison of quilting styles, but for present purposes three variables will suffice: juxtaposition of geometric shapes, juxtaposition of colors, and quilting stitch patterns. Figures 17 and 18 show two "best quilts" made by the same woman. (A best quilt is made from bought material rather than scraps and is used for guest beds.) Both quilts use geometric shapes, color contrast, and quilting stitch to create striking overall effects. Red, white, and blue in the quilt in Figure 17 accentuate the concentric diamond pattern, while a trailing vine quilting stitch highlights the white areas (see Figure 39). The quilt in Figure 18 is a repeated block 

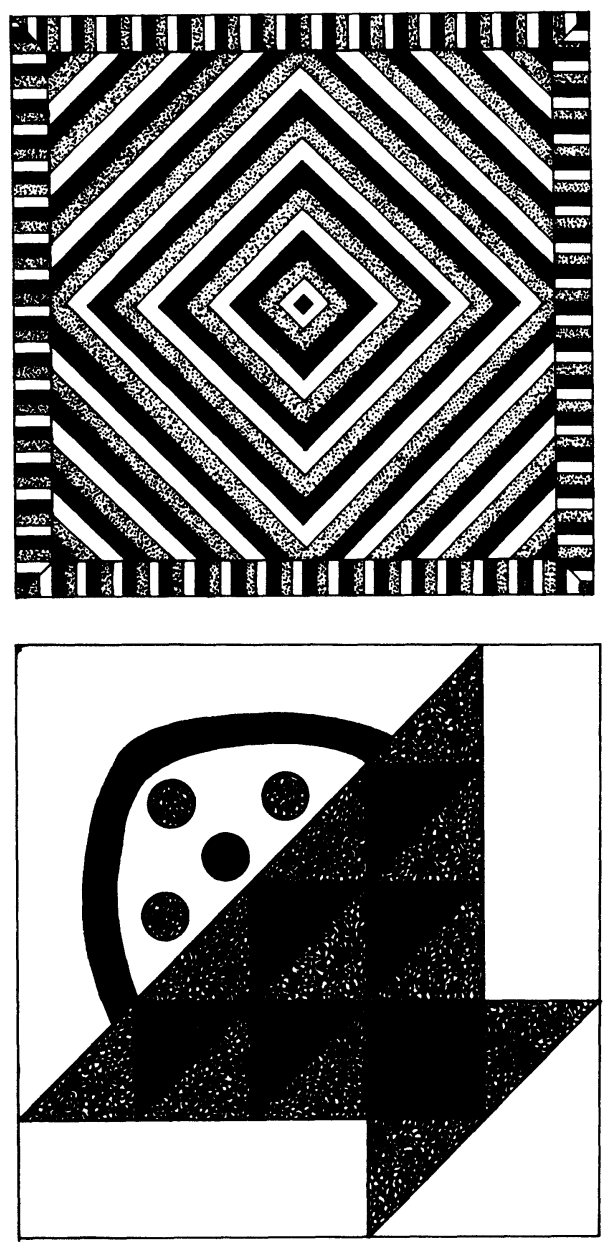

Figure 17. Quilt LG 1

Figure 18. Quilt LG 2 detail

design made up of geometric shapes smaller than in the first one. The colors are more muted, and the quilting stitch follows the basket pattern rather than add a new pictorial motif. These quilts are considered very fine both because they are aesthetically pleasing and because they required many hours of painstaking work. I have more to say about these quilts later, but for the moment I turn to the quilts of the most prolific quilter in the community.

This quilter, whom I call Florence, has a collection of eight quilts and seven unquilted tops she has made. All but one are "scrap quilts" for daily use. (A scrap quilt is made from odds and ends of material, left over from other sewing jobs or from worn-out clothes, for the use 
of family members.) An examination of this collection reveals certain aesthetic preferences that are not peculiar to Florence but common to local quilters and somewhat different from those of quilters from other parts of the South.

The quilts and quilt tops in Florence's collection could be classified in many ways. Quilt books frequently use pattern names from a standard compendium such as The Romance of the Patchwork Quilt in America (Hall and Kretsinger 1935), but (I will repeat the warning several times) Florence does not use names for her quilt patterns. As I consider the name to be an important aesthetic component of a quilt, for reasons explored below, I use a simple cataloguing scheme to refer to particular quilts. The first two letters identify the quilter by initials, the integer number identifies the pattern, and the decimal extension distinguishes quilts made according to the same pattern. Where possible the decimal extension indicates chronology. Thus FD 2.2 is a quilt made by Florence Doxey using pattern number 2, and it is her second example of this pattern. Although Florence used no names for quilts, she clearly identified quilts that used the same pattern, so that the cataloguing system records this recognition and does not identify each quilt by a separate number. Figures 19 through 29 show Florence's quilts in various degrees of detail.

To some quilters in the United States the name of the quilt is itself of no small importance. In some cases the pattern is a stylized representation of what the name suggests, such as Lone Star (Figure 30). Sometimes the relationship between pattern and name is more abstract, as in Jacob's Ladder and Flock of Geese (Figures 31 and 32). And sometimes there is no apparent relationship between name and pattern, as in Nelson's Victory (Figure 33). Quilters who use names may be consciously or unconsciously influenced by them in the production of quilts. They may, for example, be prompted to emphasize star patterns in a design with "star" in the name. Conversely, women who use no names may feel fewer constraints. They may think of all quilt designs in terms of generalized shapes rather than specific linguistic symbols and not feel the need to represent something as specific as a star, ladder, or lily. This is certainly the case in Florence's collection. Before looking at Florence's quilts in detail, however, we need to understand the components of a quilt design.

Juxtaposition of shapes and juxtaposition of color have a special relationship to the overall design of a quilt. The great majority of pieced quilt designs are made up from a few simple shapes: diamond, triangle, hexagon, and square. However, the pattern is not given 


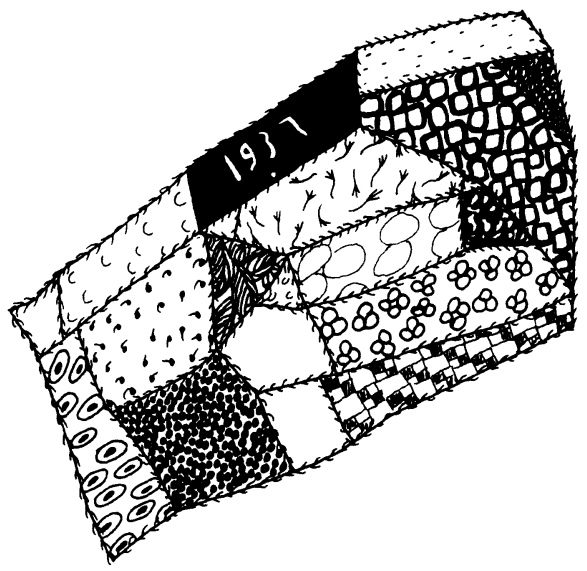

Figure 19. Quilt FD 1 detail

Figure 20. Quilt FD 2.1 detail

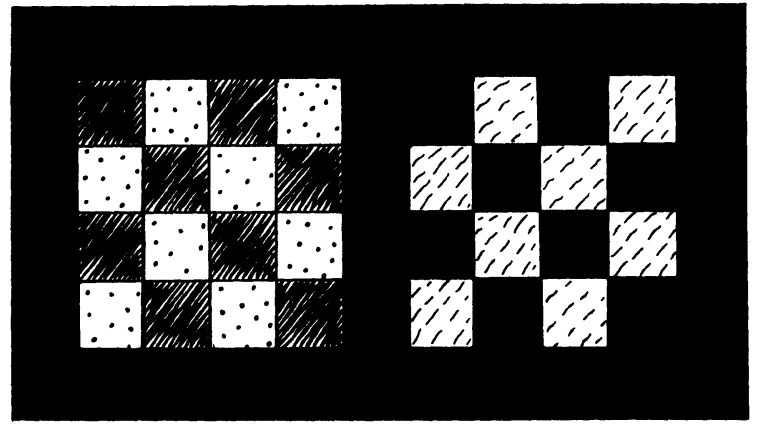

definition by the arrangement of geometric shapes alone. Choice of colors determines the overall pattern that emerges. Without color, for example, the Jacob's Ladder pattern appears as in Figure 34. Only when appropriate squares and triangles are shaded light and dark is the ladder defined (Figure 31). If the quilter chooses other shading patterns then different designs appear, such as Underground Railroad or Stepping Stones (Figures 35 and 36). One of the basic areas of creativity open to the quilter is the arrangement of colors within a basic geometric framework.

The quilting stitch, which holds the layers of the quilt together, completes the visual effect of the finished quilt. The quilter may follow the pieced design with her stitches or at least use the pieced design as a general guide (Figure 37), she may completely ignore the piecing (Figure 38), she may use large solid areas in the pieced design as frames for single motifs (Figure 39), she may create textured effects 


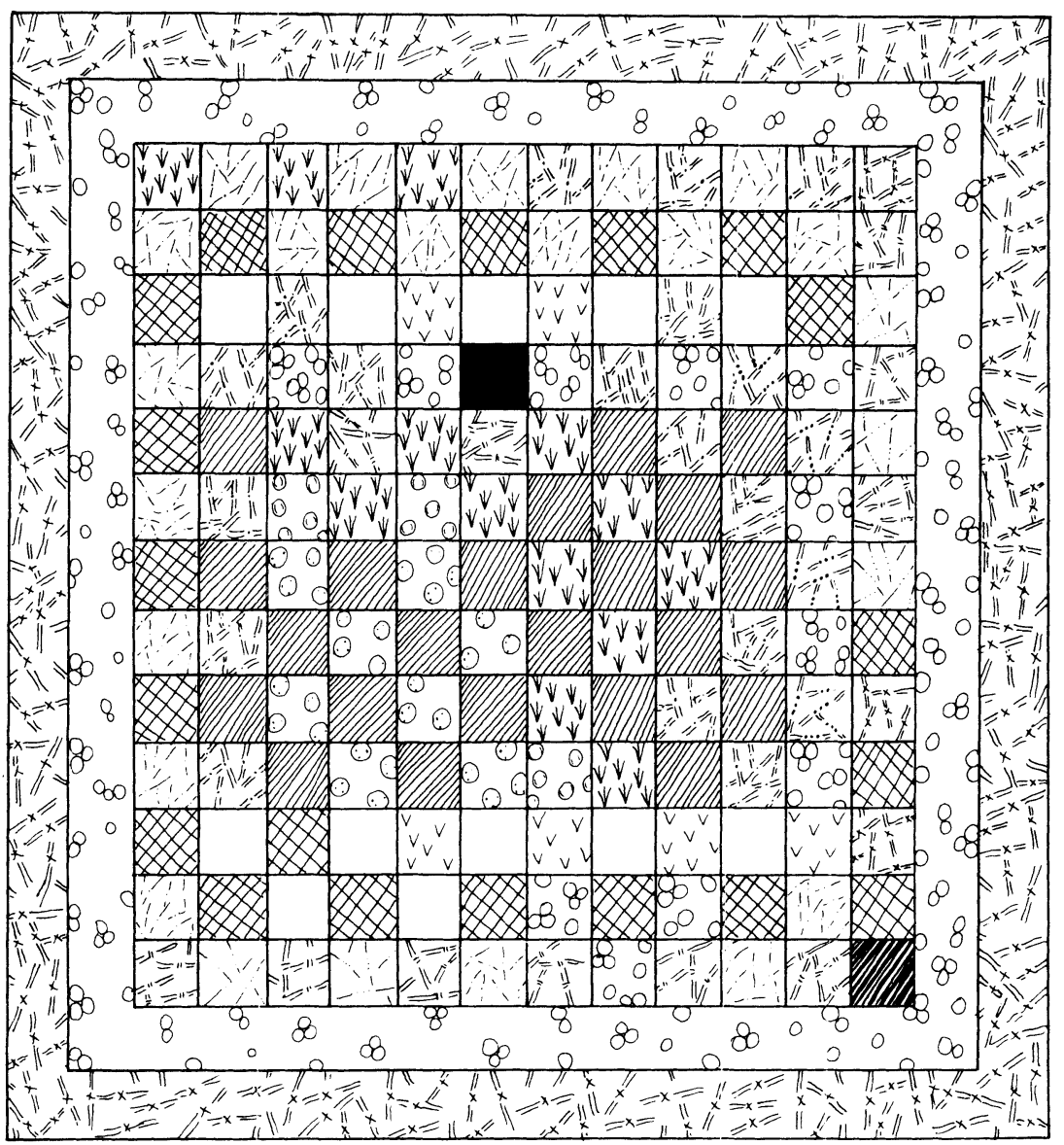

Figure 21. Quilt FD 2.2

Figure 22. Quilt FD 3 detail

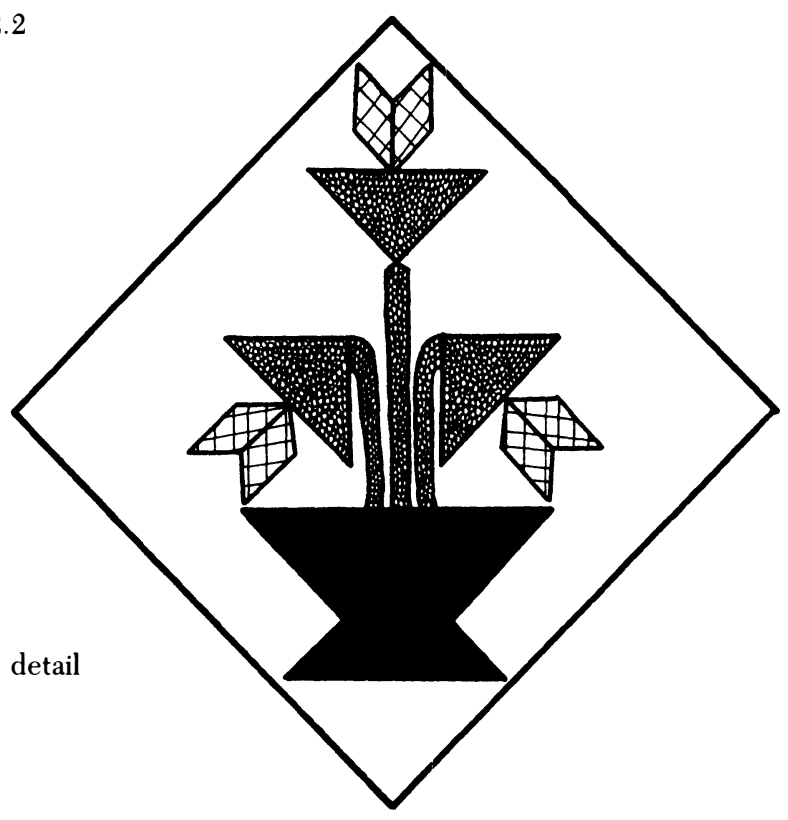


Figure 23. Quilt FD 4 detail

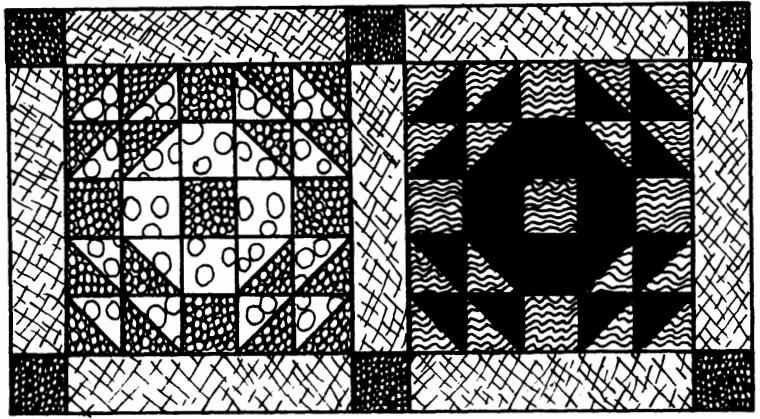

Figure 24. Quilt FD 5 detail

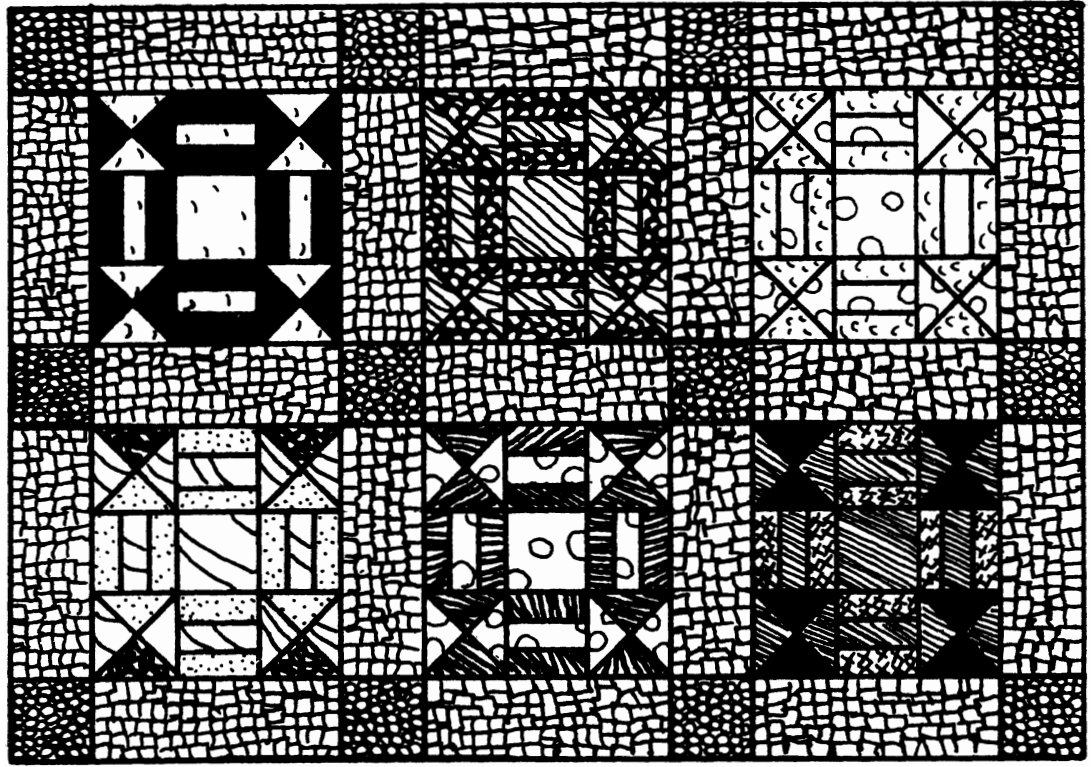

Figure 25. Quilt FD 6.1 detail

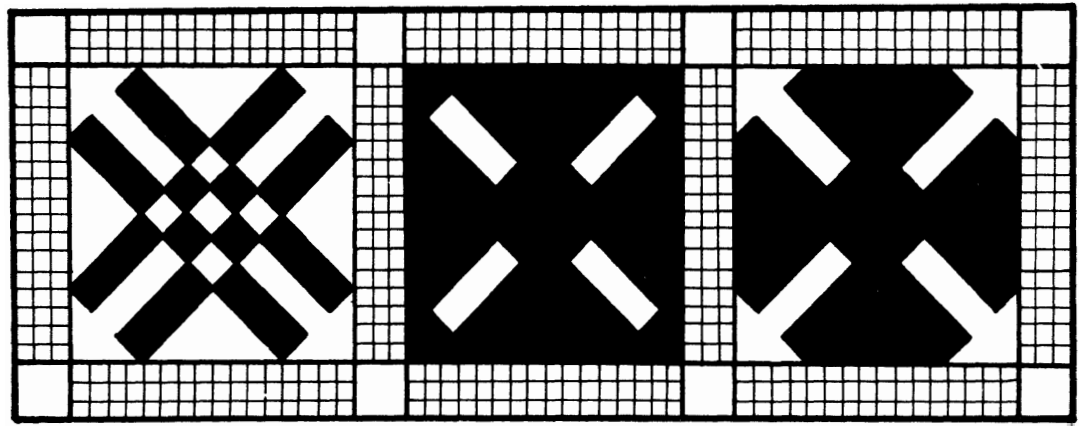




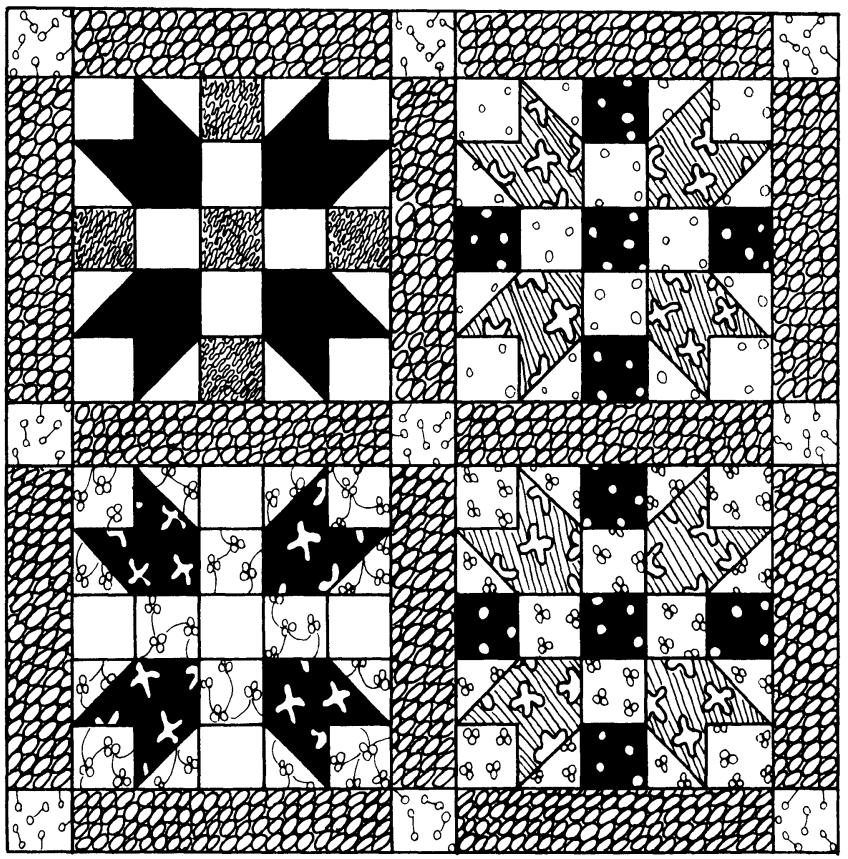

Figure 26. Quilt

FD 7.1 detail

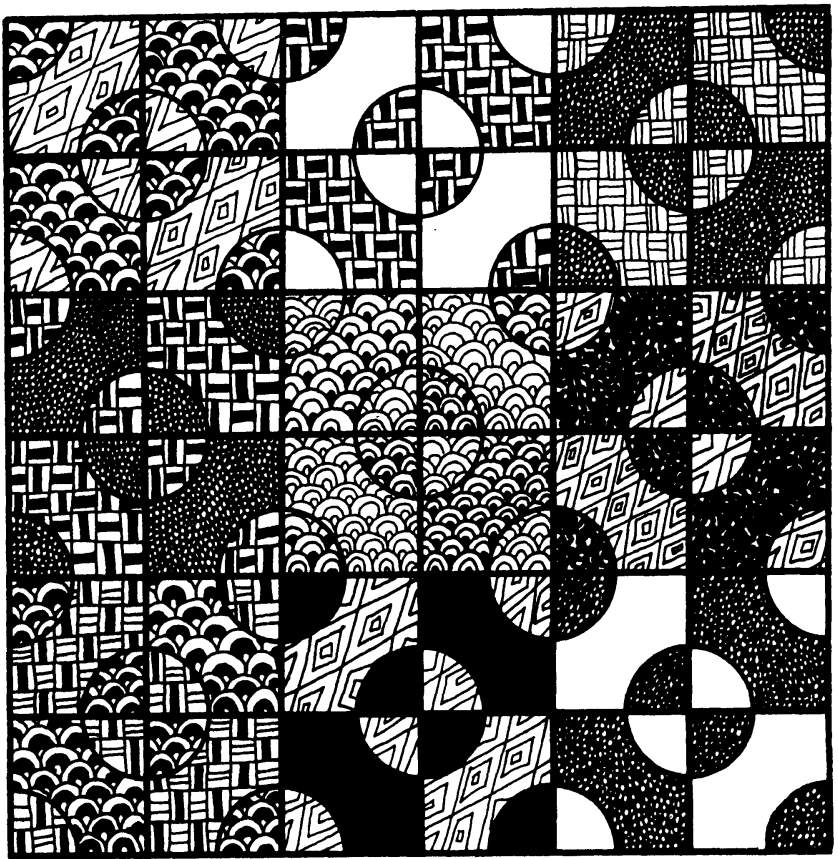

Figure 27. Quilt

FD 8 detail 

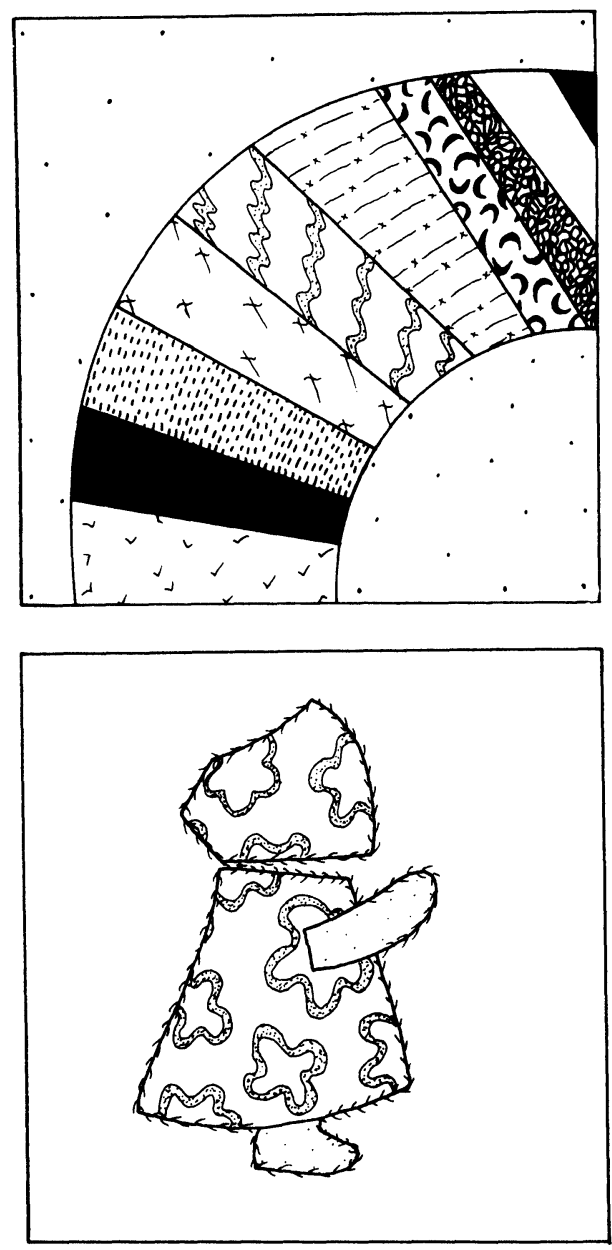

Figure 28. Quilt FD 9 detail

Figure 29. Quilt FD 10 detail

(Figure 40), or she may use any combination of these techniques. Thus the quilting may emphasize the pieced design or provide a counterpoint to it. Whatever the aesthetic relationship, however, a quilt top is three-dimensional. The texture and visual complexity added by the quilting stitch are fundamental ingredients in the final product and have too often been overlooked in design analysis. Moreover, the feel and texture of a quilt change over time as the quilt is used and washed. In other words, a quilt is not a two-dimensional, static, visual object but a three-dimensional, visual and tactile object that changes significantly through time. The history and destiny of quilts are important to any understanding of the aesthetics of quilts, and I treat them more fully later. 
Figure 30. Lone Star quilt design

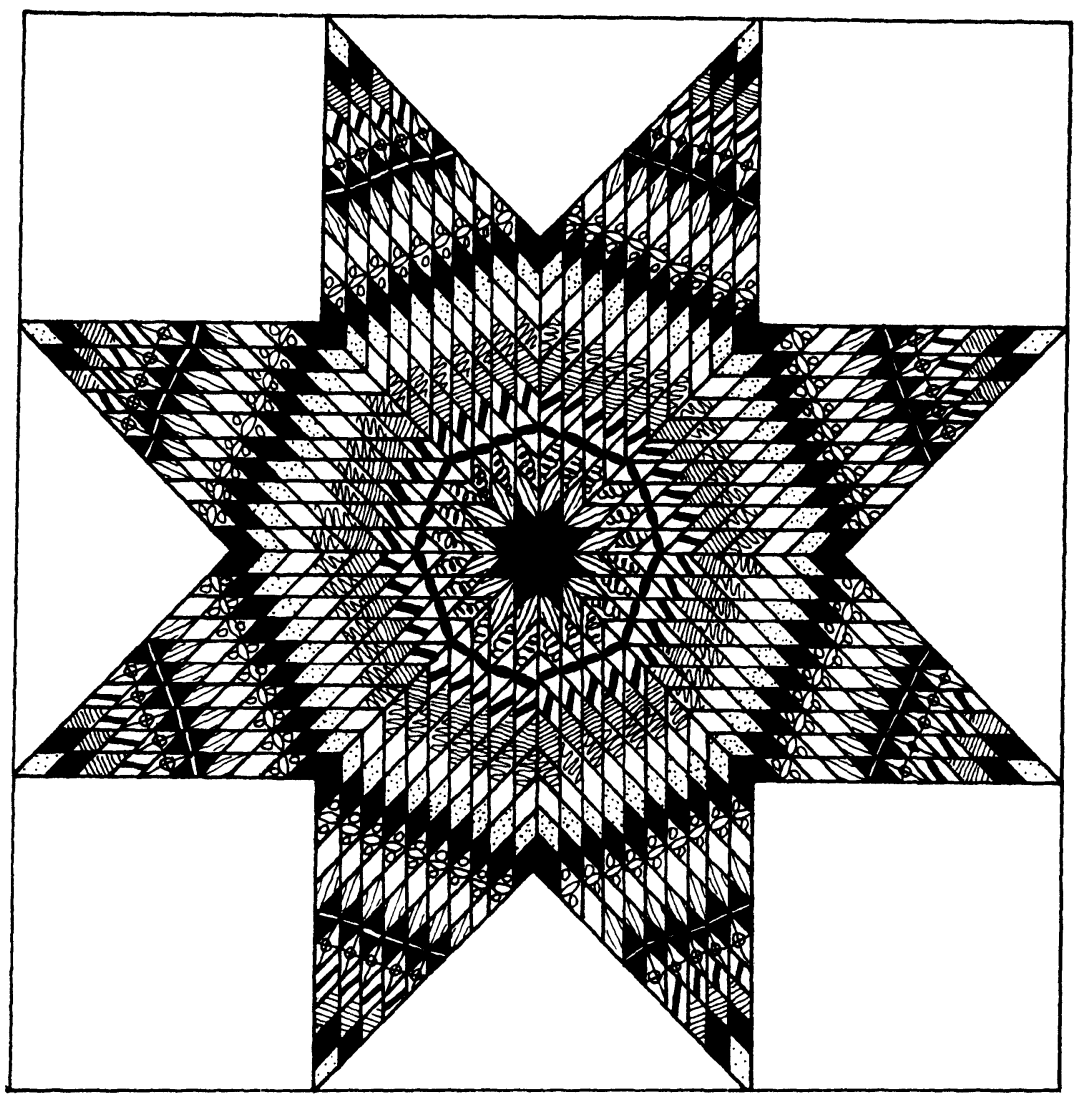

In Florence's collection most quilts are made up of repeated, incremental units. These units may be simple blocks of color, such as FD 2.2 (Figure 21), or more complex designs, such as FD 3 (Figure 22). Fourteen of her quilts are made up of repeated units, and only one, a crazy quilt, is not. In many of the quilts she has set the incremental blocks apart from one another with a set of internal borders called "sashing." These borders separate and emphasize each block. All but one of her quilts and tops have an outer border in addition to the regular binding that edges the quilt, and one has a strong double border.

The blocks within these internal and outer borders exhibit a high degree of geometric, but not color, symmetry. Of the patterns that are more than one-patch designs, nine are symmetrical around four axes and two around one. The former also exhibit $90^{\circ}, 180^{\circ}$, and $270^{\circ}$ 


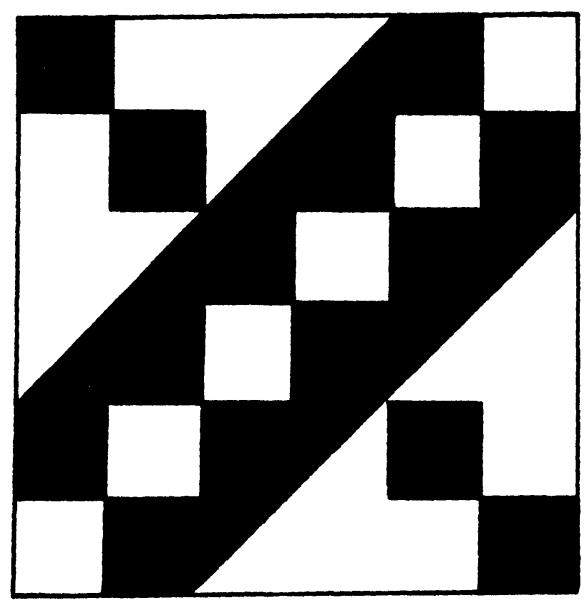

Figure 31. Jacob's Ladder

quilt block

Figure 32. Flock of Geese quilt block

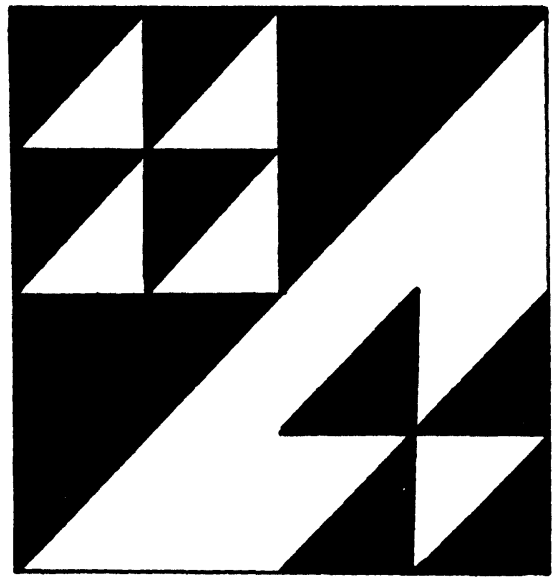

Figure 33. Nelson's Victorv

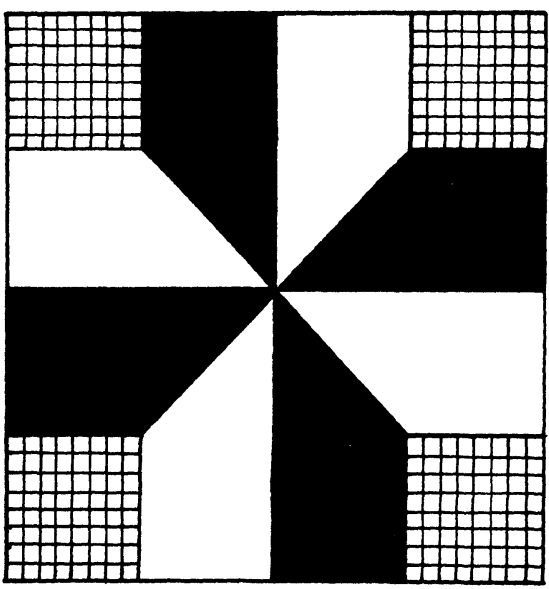

quilt block 


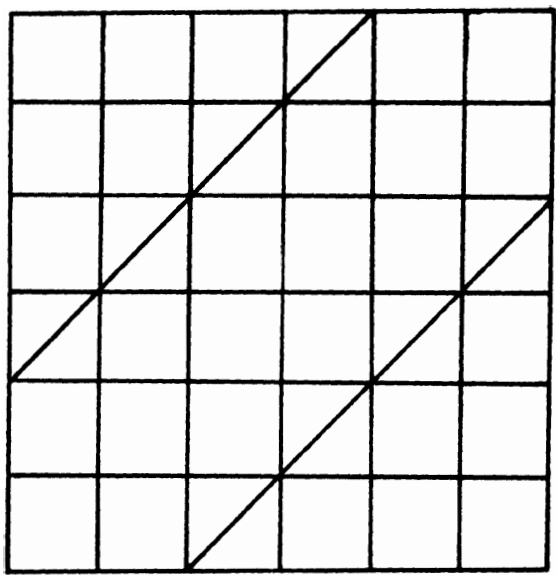

Figure 34. Jacob's Ladder uncolored quilt block

Figure 35. Underground Railroad quilt block
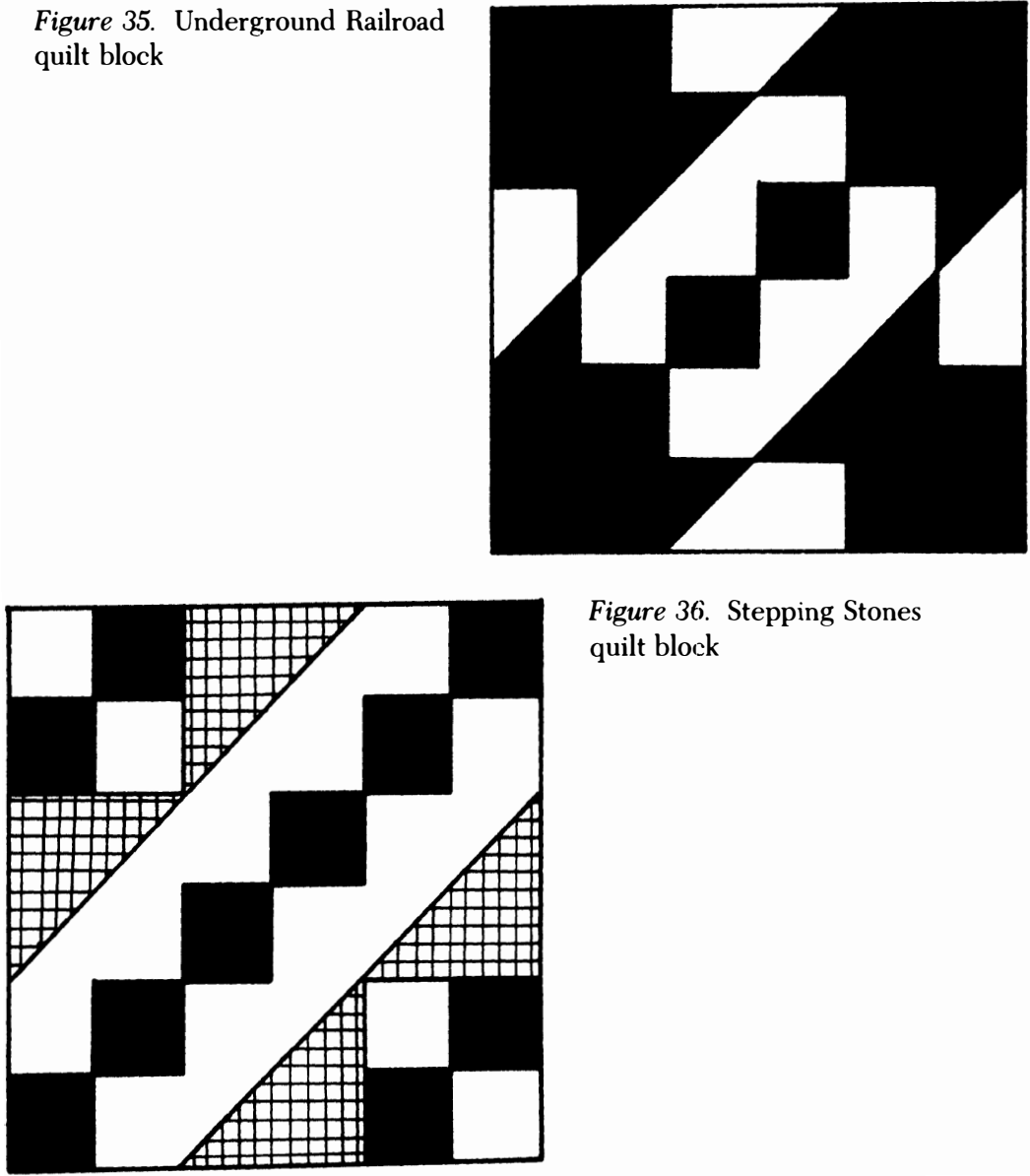

Figure 36. Stepping Stones quilt block 


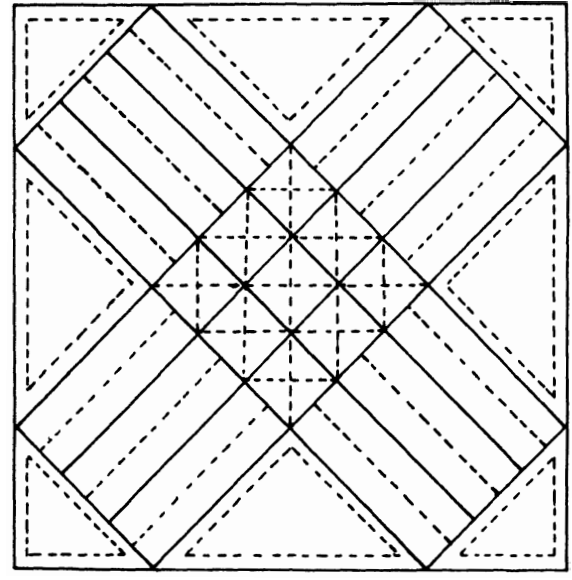

Figure 38. Curvilinear quilting stitch with rectilinear piecing design
Figure 37. Quilting stitch following piecing design (from quilt FD 6.1)

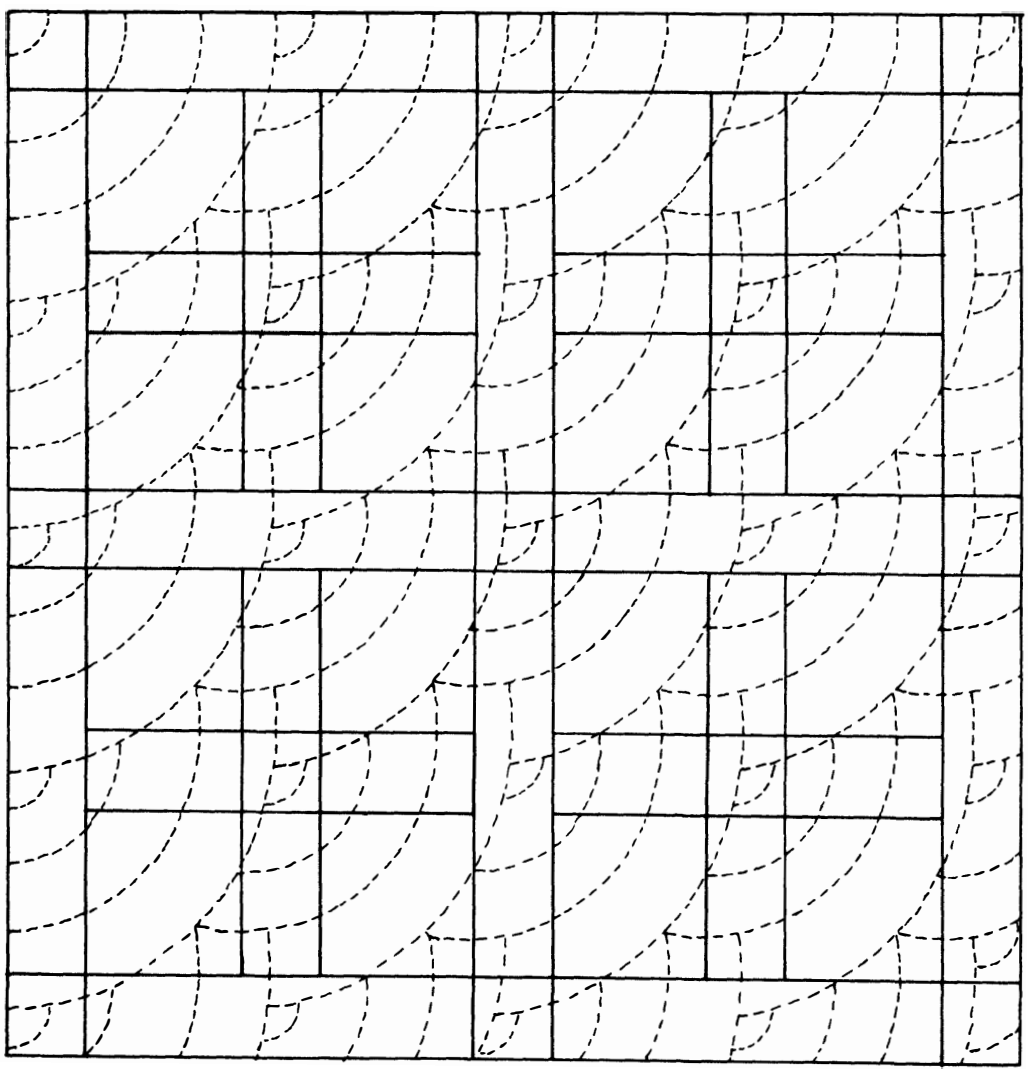



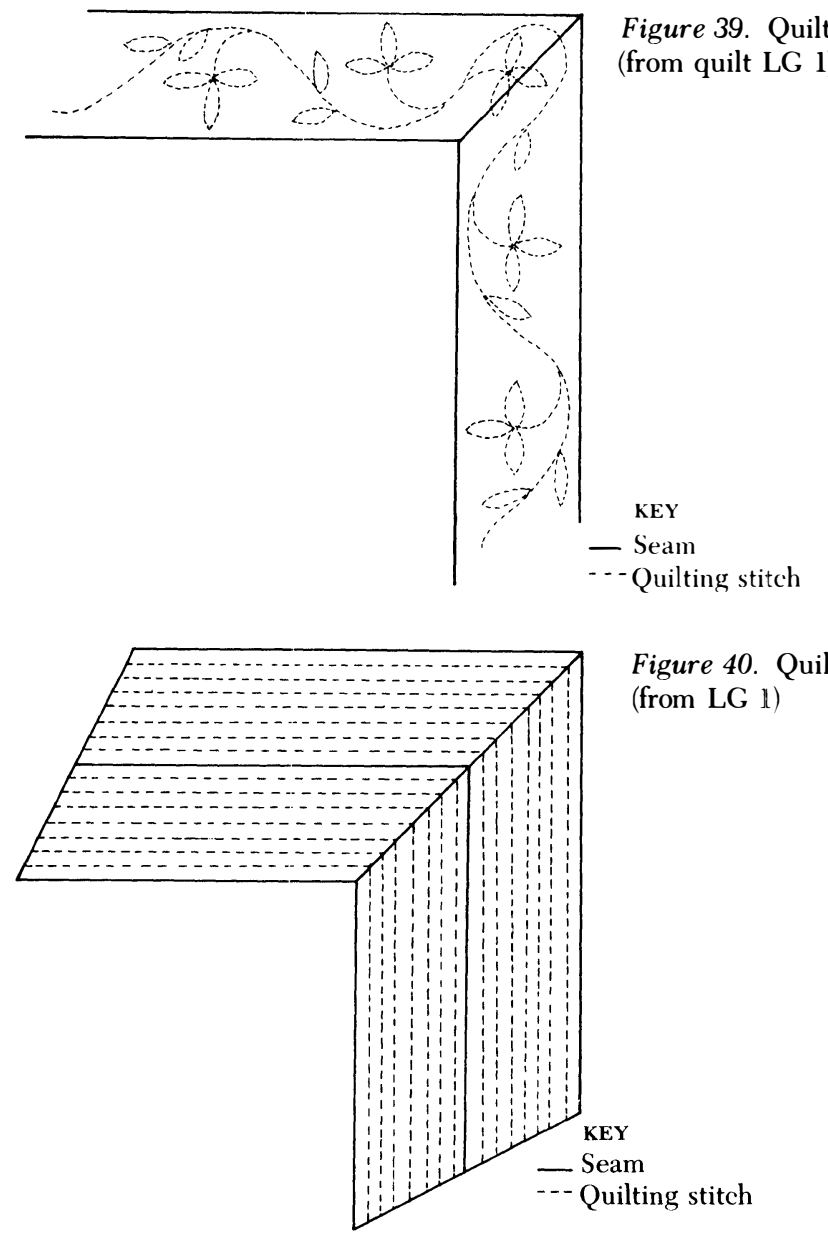

rotational symmetry. However, this high degree of symmetry, regularity, and incremental repetition is radically deemphasized by color choice. Careful examination of the quilt tops identifies little incremental repetition based on color. FD 6.1 (Figure 25), for example, is not the product of identical blocks repeated. The underlying geometry is the same in each block, but color choice makes each block markedly different. Some are highly symmetrical and others are asymmetrical; in some the geometrical complexity of the block is revealed whereas in others it is submerged. Overall, there is much more emphasis on color, hue, shade, and value than on geometry and regularity, and nowhere is this more strikingly revealed than on the one patch top 


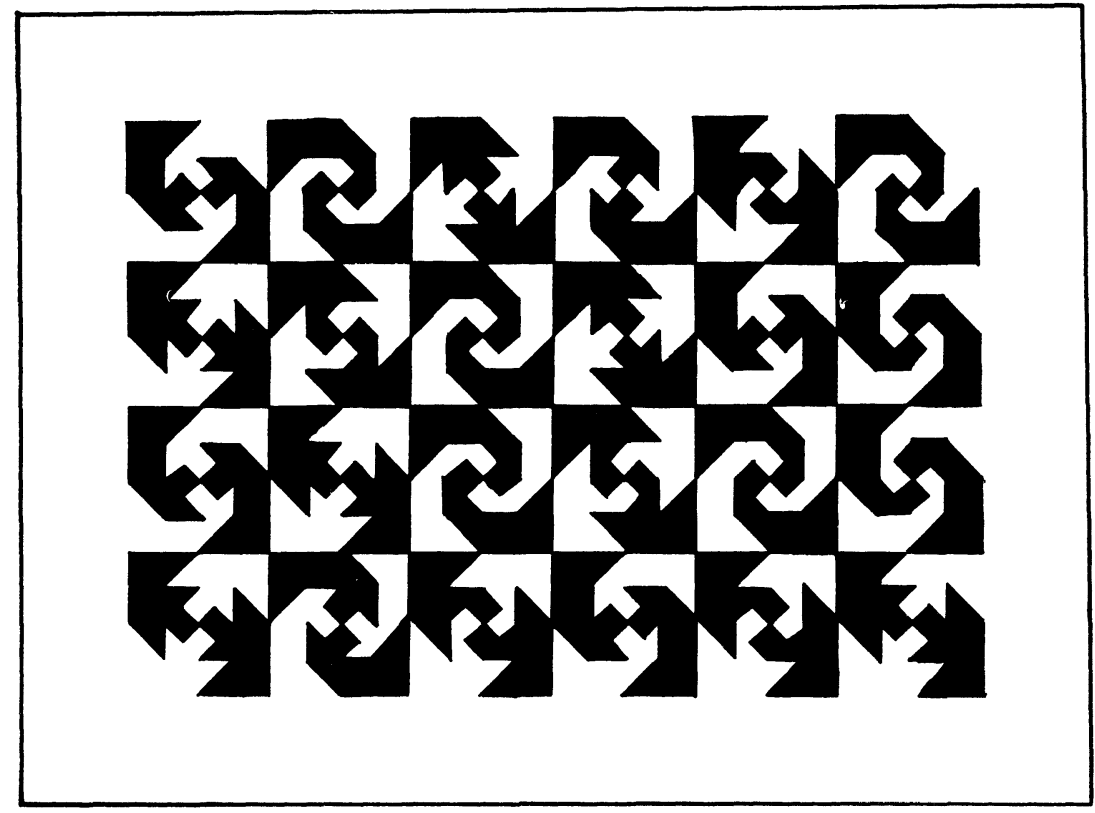

(Figure 21). Here Florence might have created a regular checkered pattern or one with a uniform color balance, but she has avoided such a mechanical approach to design. She has not arranged the colors uniformly, and the focus of attention is off center. One color is contrasted with a lighter one in one part of the quilt, with a darker one elsewhere. All of her quilts exhibit the same aesthetic qualities: geometric uniformity subordinated to complex color choice, with individual blocks contained within uniform borders.

Other quilts from Tidewater have the same basic features. The quilt in Figure 18, regular in its color choice because a best quilt, is not symmetrical overall. The baskets might have been set to form a concentric diamond pattern, but instead the pattern is broken and the diamond's center lies off center on the quilt top.

Another quilt fabricated locally uses color choice to break up the basic geometric configuration (Figure 41). The quilter evidently had sufficient material of each color to make the blocks uniform had she desired it. Instead she has created all of the possible combinations of the shapes which can be made with color choice while she preserved the underlying geometry. Figure 42 shows the basic uncolored block and along with Figure 43 reveals the method of piecing this kind of 


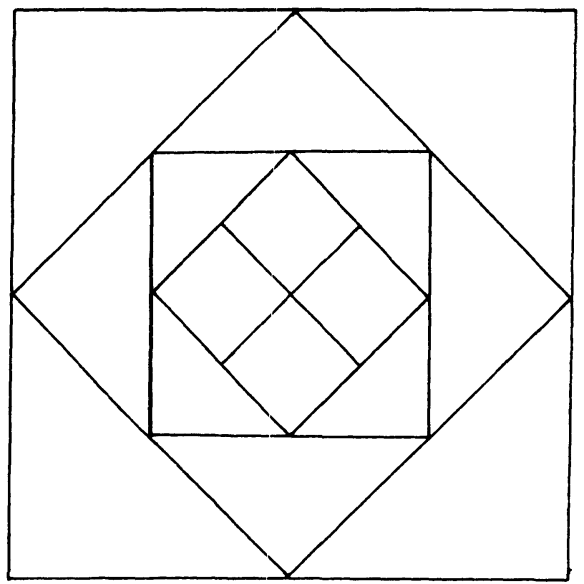

Figure 42. Quilt AN 1 uncolored block

block. First the quilter puts together four squares to make subunit I, alternating light and dark checkerboard fashion. Next she adds four right triangles to make a larger square, subunit II, again alternating light and dark. She continues adding triangles in the same fashion to make subunit III and then the finished block. One method of alternating lights and darks in the subunits produces a left-handed spiral pattern (Figure 44), another produces its mirror image, a right-handed spiral (Figure 45). But the quilter may take the left-handed spiral and rotate subunit I through $90^{\circ}$, producing a different pattern (Figure 46). She may do likewise with subunits II and III (Figures 47 and 48), or she may produce their right-handed mirror images (Figures 49-51). The simple alternation of light and dark in the subunits (which is, of course, only one method of varying the basic block) produces eight different patterns. Returning to the overall quilt, we can see that the quilter has employed all eight logical variations: she has played with design and construction technique in a series of variations on a theme. A schematic view of the placement of the different variations is shown in Figure 52.

It is also possible to arrange the blocks of this pattern to create a larger set of tessellating figures (Figure 53), but the Tidewater quilter has subordinated overall design to the individual blocks. The ultimate effect is one of considerable complexity. The effect of the tessellating pattern is to create a design unit larger than the blocks that make it up. Although the blocks in Figures 41 and 53 are drawn to the same size, the tessellating figures loom larger. Larger units may appear in the Tidewater quilt, but they are changing and ephemeral. This primacy 


\section{Aesthetics at Home}

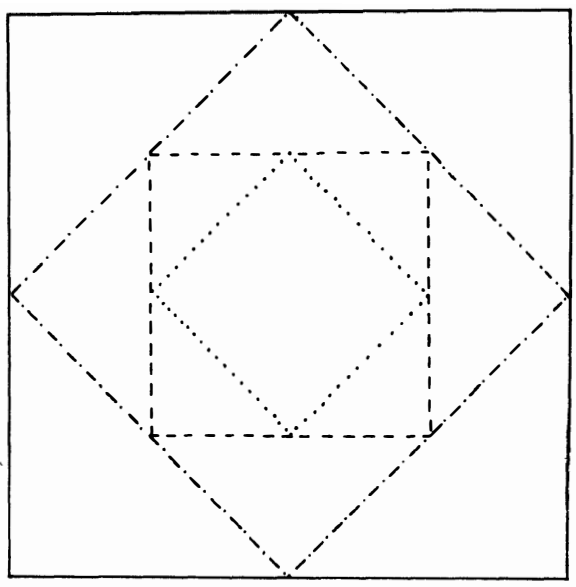

Figure 43. Quilt AN 1 showing block subunits

KEY

Subunit I

-. - Subunit II

-.. Subunit III

Figure 44. Quilt AN 1 block variation $1 \mathrm{~L}$
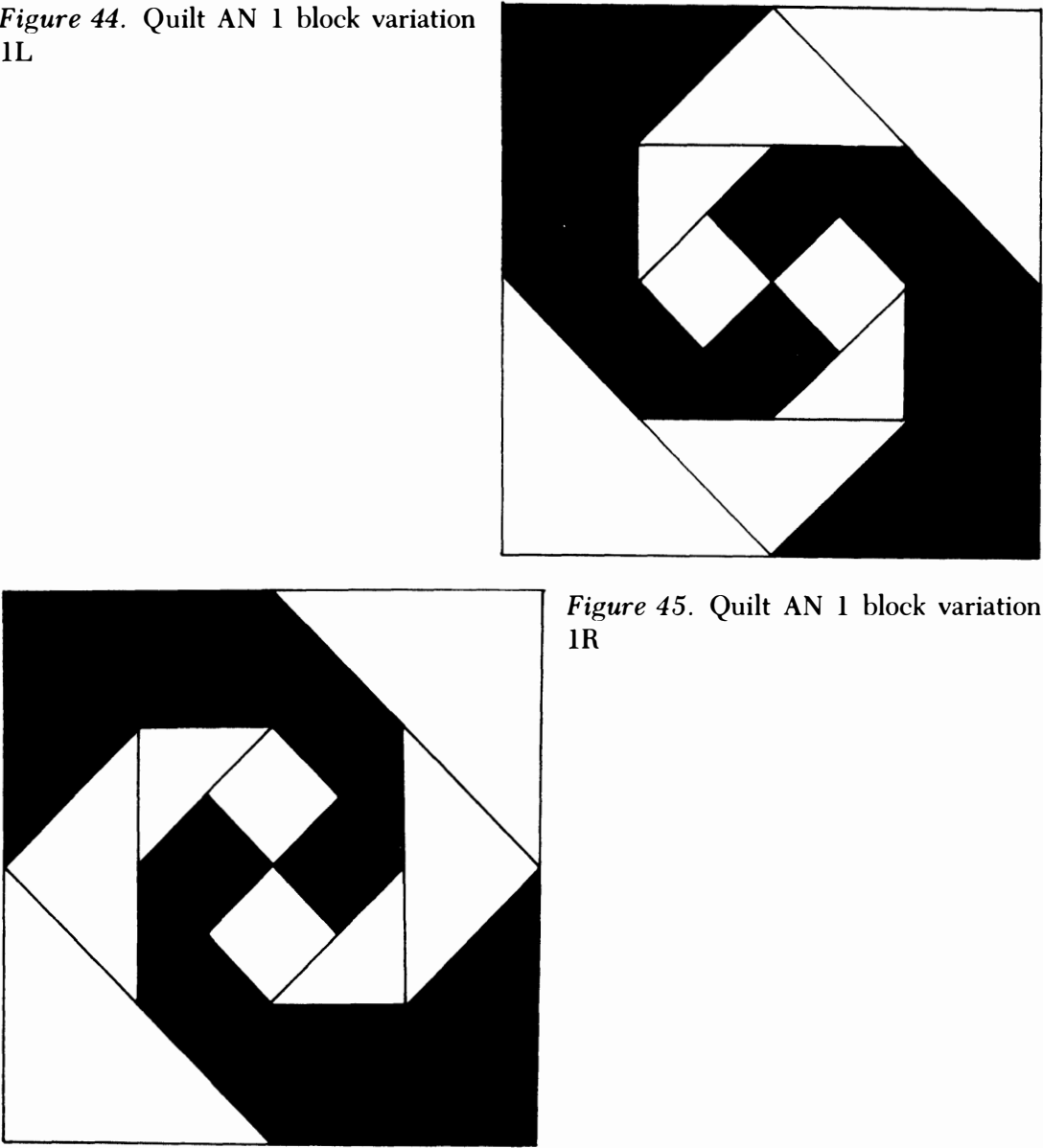

Figure 45. Quilt AN 1 block variation IR 


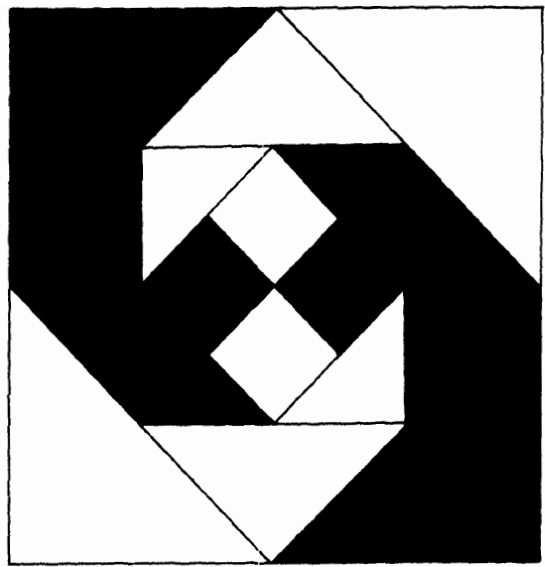

Figure 46. Quilt AN 1 block variation $2 \mathrm{~L}$

Figure 47. Quilt AN 1 block variation $3 \mathrm{~L}$
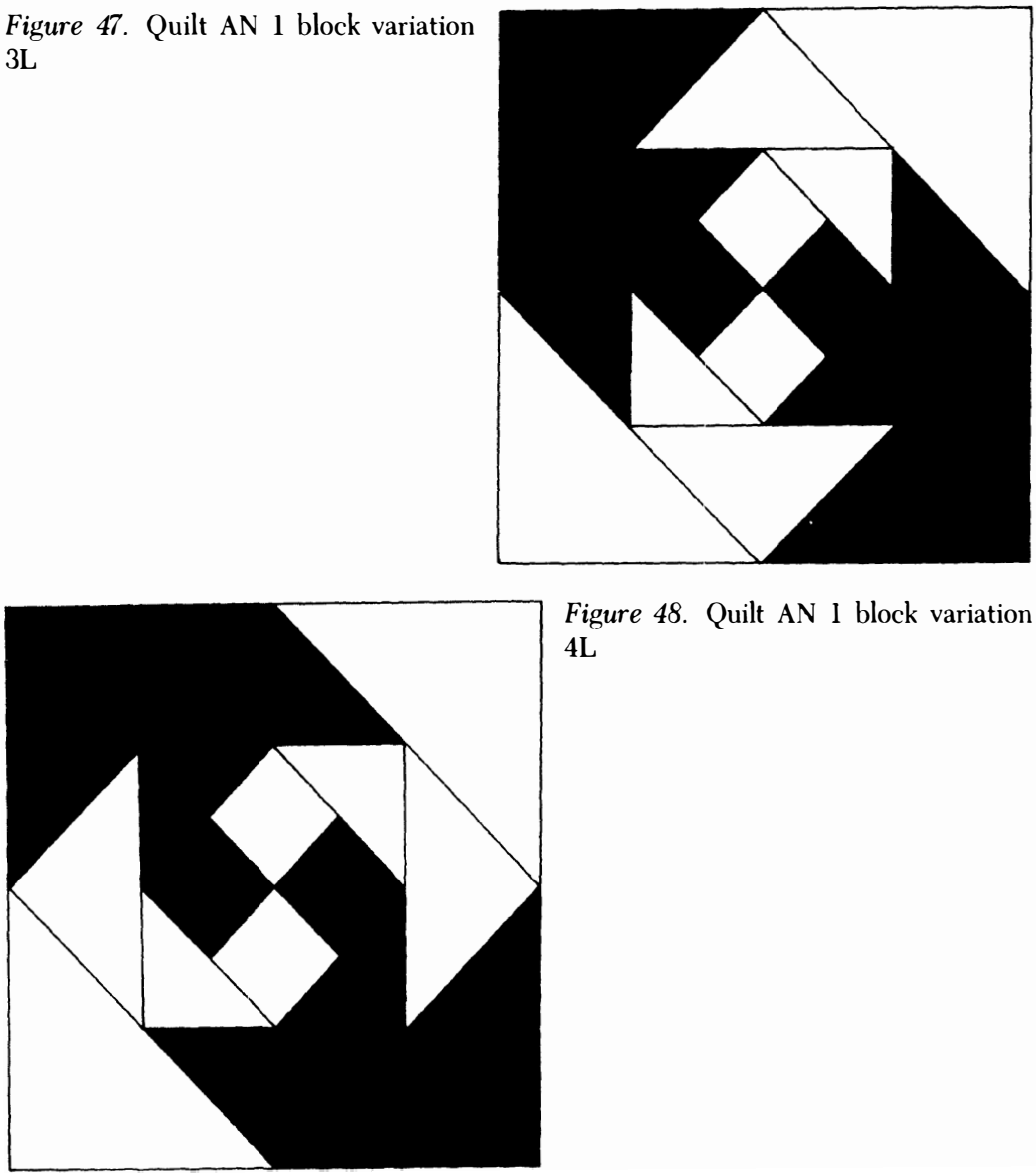

Figure 48. Quilt AN I block variation $4 \mathrm{~L}$ 
Aesthetics at Home

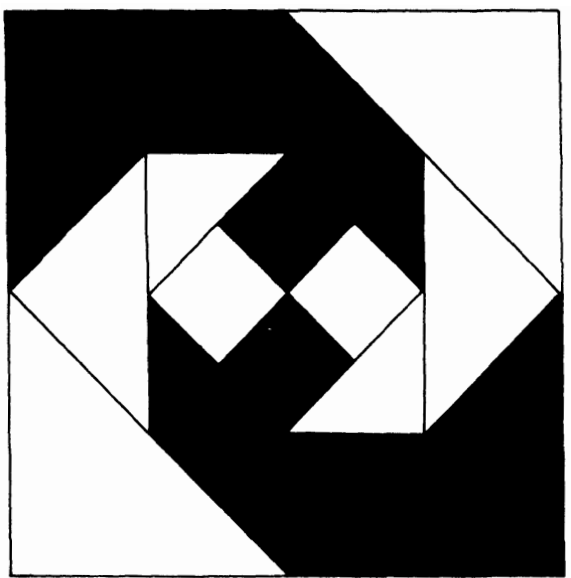

Figure 49. Quilt AN 1 block variation $2 \mathrm{R}$

Figure 50. Quilt AN 1 block variation $3 \mathrm{R}$
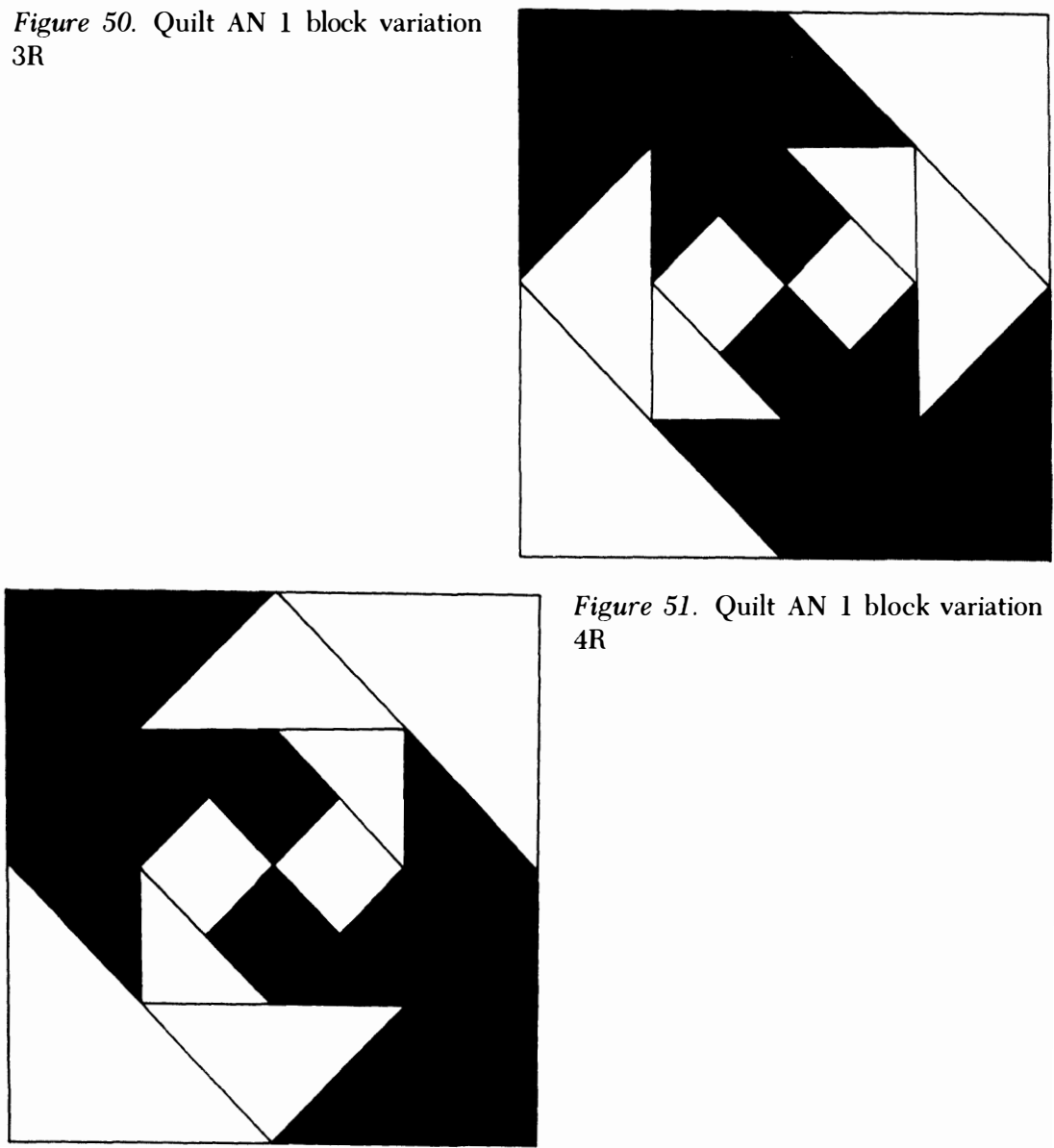

Figure 51. Quilt AN 1 block variation $4 \mathrm{R}$ 
Figure 52. Quilt AN 1. block variation scheme

\begin{tabular}{|c|c|c|c|c|c|}
\hline $2 \mathrm{~L}$ & $\mathrm{IR}$ & $3 \mathrm{R}$ & $2 \mathrm{R}$ & $4 \mathrm{R}$ & $1 \mathrm{R}$ \\
\hline $3 \mathrm{~L}$ & $4 \mathrm{~L}$ & $1 \mathrm{R}$ & $3 \mathrm{R}$ & $2 \mathrm{~L}$ & $1 \mathrm{~L}$ \\
\hline $2 \mathrm{~L}$ & $3 \mathrm{~L}$ & $1 \mathrm{R}$ & $4 \mathrm{~L}$ & $1 \mathrm{R}$ & $1 \mathrm{~L}$ \\
\hline $3 \mathrm{~L}$ & $2 \mathrm{R}$ & $4 \mathrm{R}$ & $2 \mathrm{~L}$ & $4 \mathrm{R}$ & $3 \mathrm{~L}$ \\
\hline
\end{tabular}

Figure 53. Quilt AN 1 block variation $1 \mathrm{~L}$, repeated in a tessellating design

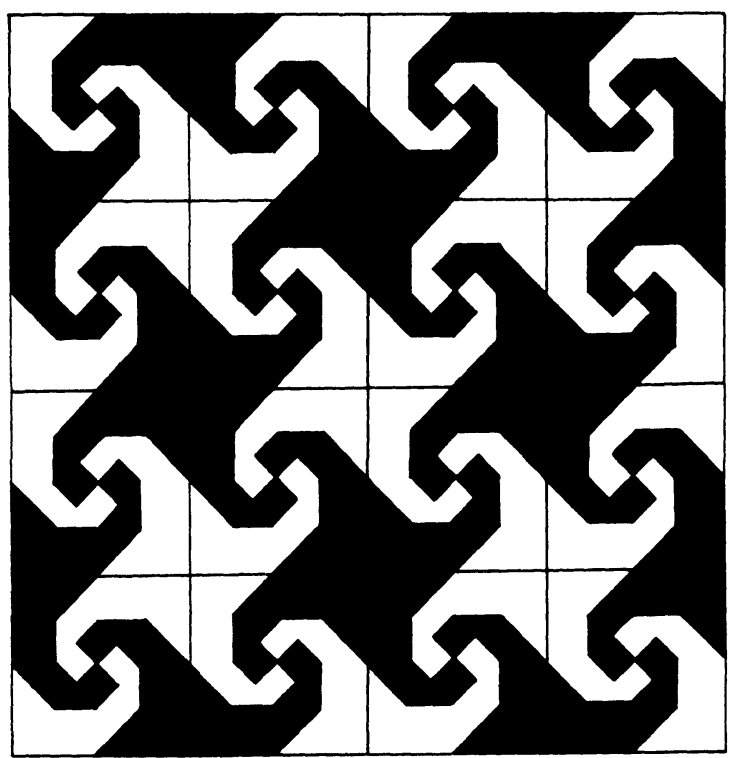


in construction of the block unit over larger patterns is a general aesthetic principle in all local quilts. Internal borders, or sashing, around the blocks often help emphasize the block as the primal unit. Where sashing is absent, color choice preserves the integrity of individual blocks (see for example Figure 27).

As a general rule the scrap quilts of Tidewater exhibit a wide degree of freedom in color choice and variations on a theme, whereas the best quilts are regular in color and show few variations from block to block. The simplest and most usual reason given for these differences is that the scrap quilter is making do with whatever is on hand but the best quilter can buy enough material of each color to make all of the blocks uniform. But the quilt just analyzed gives the lie to this supposition. The quilter had enough light and dark material to make every block the same and to make a tessellating pattern. She did not make the quilt regular because she chose not to. The main reason is that best quilts are for public display and scrap quilts are for private use. The aesthetic values in the two realms are diametrically opposed.

Although the quilters of Tidewater use color choice to deemphasize underlying geometric patterns, their quilting stitches emphasize them. In all but one of Florence's quilts the stitches follow the edges of the geometric pattern (see Figure 37). The same is true of most other quilts made in Tidewater. Of the three variables, geometry, quilting stitch, and color, the first two show marked regularity and uniformity in all kinds of quilts, and the last involves a high degree of freedom and creativity in scrap quilts but is regular in best quilts.

The process of fabricating quilts in Tidewater is slightly unusual in comparison to many parts of the United States, where the production of a quilt is partly a joint effort. One or several women piece a number of tops, assemble sufficient batting and backing for all of the tops, and then invite friends to a quilting bee at which they quilt the three layers together following patterns marked by the owner. In Tidewater quilts are made from start to finish by one woman without the aid of others. This lack of joint effort mirrors the social realities of a Tidewater woman's life. Women do have small groups of friends who meet on regular occasions to play bridge, go grocery shopping, and perform chores that need several pairs of hands. But general social visiting is extremely rare. Many women told me they never visit their friends for a chat if they are well but will visit as of ten as possible in times of crisis. As one woman put it, "People here are not much on visiting you as long as you're getting along all right. But if you have a problem, get in trouble, they all rally round to help you." Her characterization was borne out by my personal observations. At one point Florence was 
hospitalized for two weeks, and when she returned home she had a constant stream of visitors. In fact, she had so many visitors that on several days there was not a moment from sunrise to sunset when a friend was not in her sitting room, chatting. Before her hospital stay her only visitors had come for a specific task.

It is also true, as older needleworkers told me on several occasions, that every woman quilts in a slightly different fashion. Thus a quilt worked by many hands might be uneven in its overall stitchery. Singlehanded quilting obviates this problem.

The fact that quilts are made from start to finish by one woman affects them as aesthetic objects. Most quilters do not show their quilts to other women and display them in parts of the house closed to routine visitors, that is, the bedrooms. Quilts are not made for general public scrutiny or approval but are objects of private aesthetic value. Of course, best and scrap quilts are different: the former are used in guest bedrooms and are therefore on show to a limited public. The differences between the two types of quilt are highly suggestive. Best quilts use expensive materials, and are regular and uniform. Energy and artistry goes mainly into elaborate, painstaking quilting stitches, and best quilts are tributes to their makers' commitment to hard work. Scrap quilts are for family use only and allow the quilter to indulge her aesthetic fancies without adverse comment, since they will not be judged by outsiders. They may show an element of play that is missing in best quilts. These aesthetic decisions may be ultimately tied to the Protestant work ethic. That is, public craft should reflect well on a woman's industry and her ability to shrug off tedium, so best quilts are highly repetitive in design, with elaborate careful and uniform stitching. In private, however, a quilter may play as she works.

Scrap quilts, perhaps because they are made as fancies, are not cherished objects in the way that best quilts are. Best quilts are kept packed in camphor chests and brought out with reverence on special occasions. When they become too old to use, they are carefully washed and packed away as treasures. At this point they become like conceptual art works in that they may be stored in such a way that no one can ever see them. Some, for example, are cleaned, mothproofed, and stored in hermetically sealed bags. They are then permanently hidden from view, public and private, and discussed reverentially. Scrap quilts, on the other hand, are used and reused, roughly washed in the washing machine until they are shreds, and then demoted to some more mundane function. The pleasure of their creation does not make them lasting objects; quite the opposite. A quilt that was a 


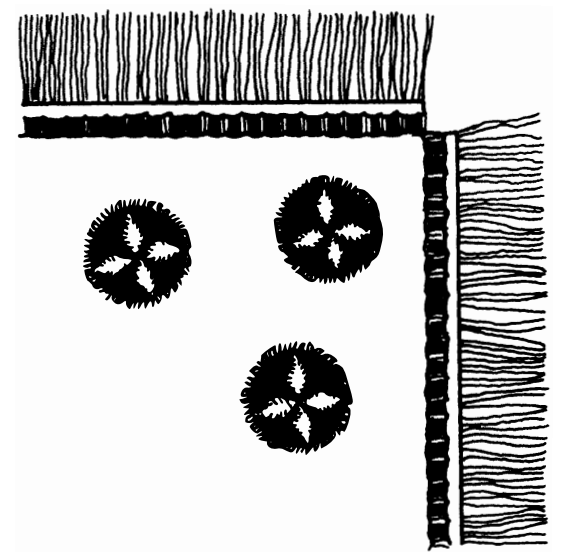

Figure 54. Cutwork placemat detail

pleasure to make is destined for ultimate destruction. I observed scrap quilts that had become shreds used as rags to clean motors, furniture pads, ironing-board covers; and one that had been especially tricky to piece because it involved a variety of inset diamond shapes ended its days as a shroud to bury a beloved family dog. Over the course of their lives these scrap quilts sof ten in color and texture, and several women commented on this process as desirable. They loved the feel and look of an old, well-worn, well-washed favorite. But this soft quality is the precursor to the material wearing so thin that it splits and tears, and then the quilt's days are numbered. From all of this we may derive a principle that applies to women's aesthetics in general, namely, that which is made with effort is of lasting value but that which is a joy to make has a limited duration. Best quilting is work, scrap quilting is leisure.

Elaborate embroidery, needlepoint, and cutwork are much more a thing of the past than quilts are. Some of the older women still quilt, but no one does fancy needlework. Those items which decorate homes are all treasured heirlooms, their owners confessing they are unable to do such work (Figure 54). Virtually all of these pieces were made at the turn of the century by younger women who had been trained in these crafts at boarding schools. These were the daughters of the few men in the town who could afford to pay for such an education: one kept a store and hotel, another was a doctor. When these girls came home from school, and before they were married, they visited one another regularly and stitched while they talked. This behavior contrasts to the more common practice in modern Tidewater of a woman doing her needlework alone, as in the case of quilting. The difference 


\section{Lord I'm Coming Home}

is undoubtedly a measure of economic standing. Most women in Tidewater pick up and put down their stitchery, snatching time for it between household tasks. The girls who embroidered had no chores, however, because the menial jobs around the house were performed by hired workers. Consequently they could visit when they pleased. But once they had children, these visits stopped. Their children, now in their seventies, display their needlework as mementos of a lost, genteel era. Such mementos also serve as subtle class markers for their present owners, indicating that their parents and grandparents belonged to a leisured class.

In modern times home-oriented, group leisure activities are few. Before the advent of television the home was one of many centers of leisure activity. Peer groups, especially youths and young adults, gathered to dance, sing, and play games. The older men and women in town remember these activities fondly and point to television as the cause of their demise. One man described television as "the greatest curse that's ever hit the United States. It adds nothing to you and it takes your time away from you." Before television, he said, "we had little dances, square dances mostly, when I was a kid. Once in a while we'd have a candy pulling. Five or six or a dozen young girls and boys would get together and they'd have a candy pulling. Most all the girls could play a piano. When it got into the eighteens and nineteen and twenty everybody had pianos that wanted them." One member of this generation who regularly played the piano for dances or singing parties has preserved a stack of sheet music-art songs, popular songs of the twenties, vaudeville songs, and college songs. On very rare occasions now two or three women gather at a piano or home organ to sing, but these are extraordinary events. The community at one time also had two fiddle players who played for dances at home. But the fiddle always had a suspect reputation, as the following story attests:

My grandfather was a fiddler and played for dances. I reckon that in my family there was a religious streak going right on down the family. It's in me. He used to play for dances back in the old days. He had a dream one night. And I don't remember the details, but I remember the outstanding things. Evidently there must've been some kind of subconscious conviction laying on his mind that he ought not to do it. He had a dream one night. Seems that he dreamed that he was playing for a dance, and that his fiddle-they called them fiddles in those days. I was a good-sized boy before I ever knew it was a violin-but his fiddle just broke open and a lamb's head rolled out down at his feet. And that was the last dance he ever played for. 
The home now is rarely a place for any structured leisure activities. There are occasional parties on special days, such as birthdays, but regular gatherings are uncommon. If one thread runs through home leisure, it is that it is a predominantly female activity. Males of all ages spend their leisure hours outside the house, whereas the inside of the home is the woman's world. Those parties which are given are organized by women, and men participate with a thinly disguised reluctance. The local bridge club is a women's affair. The club meets at each member's home in turn, and the hostess of the night prepares for all of the women a dessert to be eaten with tea, coffee, or cola between the second and last rubbers of the evening.

Today television viewing is the most common home leisure activity. A few women gather to watch special shows, such as favored soap operas, but generally television keeps people isolated in separate houses. Should one follow local sentiment and see television as the modern cause of this isolation? The ethnographic evidence is ambiguous. Home parties are perhaps rarer but they do still exist, and, on the other side, many factors kept women isolated before the advent of television. As far back as living memory allows, women have worked alone in their own homes: to visit another woman during the day without a specific purpose is tantamount to idleness, quilting alone is the norm and always has been, and often when women do work together at home, as in preparing the evening meal, they are close kin. If women wish to congregate for work or other purposes, they do so outside their homes, most notably at the church. There, as we shall see, communal effort is normal. 